Article

\title{
Designer Amyloid Cell-Penetrating Peptides for Potential Use as Gene Transfer Vehicles
}

\author{
Chrysoula Kokotidou ${ }^{1,2}$, Sai Vamshi R. Jonnalagadda ${ }^{3}$, Asuka A. Orr ${ }^{3}{ }^{(0)}$, George Vrentzos ${ }^{4}$, \\ Androniki Kretsovali ${ }^{4}$ (D), Phanourios Tamamis ${ }^{3, *}$ and Anna Mitraki ${ }^{1,2, *}$ \\ 1 Department of Materials Science and Technology, University of Crete, 70013 Heraklion, Grete, Greece; \\ chkokoti@hotmail.com \\ 2 Institute of Electronic Structure and Laser (IESL) FORTH, 70013 Heraklion, Crete, Greece \\ 3 Artie McFerrin Department of Chemical Engineering, Texas A\&M University College Station, \\ TX 77843-3251, USA; vamshij@tamu.edu (S.V.R.J.); asukaorr@tamu.edu (A.A.O.) \\ 4 Institute of Molecular Biology and Biotechnology (IMBB) FORTH, 70013 Heraklion, Crete, Greece; \\ vrentzos@imbb.forth.gr (G.V.); kretsova@imbb.forth.gr (A.K.) \\ * Correspondence: tamamis@tamu.edu (P.T.); mitraki@materials.uoc.gr (A.M.); Tel.: +1-979-862-1610 (P.T.); \\ +30-2810394095 (A.M.)
}

Received: 25 November 2019; Accepted: 16 December 2019; Published: 18 December 2019

\begin{abstract}
Cell-penetrating peptides are used extensively to deliver molecules into cells due to their unique characteristics such as rapid internalization, charge, and non-cytotoxicity. Amyloid fibril biomaterials were reported as gene transfer or retroviral infection enhancers; no cell internalization of the peptides themselves is reported so far. In this study, we focus on two rationally and computationally designed peptides comprised of $\beta$-sheet cores derived from naturally occurring protein sequences and designed positively charged and aromatic residues exposed at key residue positions. The $\beta$-sheet cores bestow the designed peptides with the ability to self-assemble into amyloid fibrils. The introduction of positively charged and aromatic residues additionally promotes DNA condensation and cell internalization by the self-assembled material formed by the designed peptides. Our results demonstrate that these designer peptide fibrils can efficiently enter mammalian cells while carrying packaged luciferase-encoding plasmid DNA, and they can act as a protein expression enhancer. Interestingly, the peptides additionally exhibited strong antimicrobial activity against the enterobacterium Escherichia coli.
\end{abstract}

Keywords: computational biology; molecular dynamics; peptide; amyloid; scaffold; gene transfer

\section{Introduction}

The development of biocompatible, efficient, and stable carriers for the delivery of nucleic acids into eukaryotic cells to restore or correct deficient gene products to normal expression levels garnered increased interest in the field of gene therapy. Optimal carriers package the DNA molecule efficiently into a stable complex that can bind and access cells, avoid degradation, and release nucleic acids to the nucleus for gene expression or in the cytosol for gene regulation [1-3]. Common hurdles are the inefficient delivery of nucleic acids in their naked form into the cells, due to their strong negative charge that inhibits their internalization, and their susceptibility to nucleolytic enzymes. This led to the development of a variety of non-viral vectors that can incorporate genetic material and efficiently deliver it into the cells [4]. One such vector comprising short cationic peptides called cell-penetrating peptides (CPPs) recently emerged. CPPs have the capacity to effectively cross cellular membranes, have limited toxicity, and could function as transfection carriers for nucleic-acid cargos including small interfering RNAs (siRNAs) and plasmids [5]. 
CPPs typically consist of 5-30 amino acids rich in arginine and lysine amino-acid groups, which are positively charged due to their protonation at neutral $\mathrm{pH}$. Various energy-dependent or -independent [6] internalization mechanisms were proposed [7], including the interaction of the positively charged residues with the negatively charged phospholipids of the cell membrane to facilitate direct internalization and endosomal uptake via endocytic pathways [8,9]. Due to their ability to penetrate cellular membranes, CPPs could enhance the transportation of conjugated bioactive cargos, which in turn could initiate the expression or function of specific intracellular targets. These bioactive cargos can be conjugated with the CPPs through a covalent bond or through a non-covalent complex formation [4].

The mechanism proposed for the formation of a non-covalent complex and subsequent DNA transduction involves the complexation through electrostatic interaction of the positively charged amino acids of the peptide with the negatively charged nucleic acids and the further internalization of the newly constructed complex into the cell. The complexation of the CPPs with DNA and the subsequent transportation of the peptide-DNA complex through the cell membrane could engender the enhancement of gene transfer, as well as the protection of DNA against enzymatic degradation [10].

Extensive lists of peptide carriers or enhancers of the expression of a gene of interest into cells were proposed that facilitate the non-covalent peptide-DNA complex formation. Among others are the highly cationic TAT peptide that can directly penetrate the plasma membrane as a polyelectrolytic complex upon interacting with plasmid DNA [10], amphipathic $\alpha$-helical peptide NF55 [11,12], and the PepFect14 peptide vector [13]. Highly cationic peptides, especially polyarginine (nona-arginine, R9) and the T22 peptide (RRWCYRKCYKGYCYRKCR), when fused to the $N$-terminus of GFP along with a His-tag at the C-terminus were recently reported to mediate self-association into nanosized particles that penetrate cells $[3,5,6]$. These nanosized particles can be exploited for the targeted delivery of both nucleic acids and protein drugs. Very recently, a novel category of promising AMPs was reported, based on a number of bacterial aggregation-prone regions (APRs) which are not toxic to mammalian cells but can induce protein aggregation in the bacterial cell, leading to loss of the bacterial proteostasis and eventual bacterial cell death $[14,15]$. It seems, therefore, that properly designed protein and peptide aggregates in either synthetic or recombinant form could be amenable to rational design targeting cell penetration and drug or DNA delivery. Cationic, amyloid-forming peptides are also considered promising nanomaterials for boosting gene transduction by utilizing the positive charges on the fibrillar nanosheet formed by the peptides to capture nucleic acids and virion particles and subsequently promote their cell attachment and fusion [16-20].

Amyloid aggregation of initially correctly folded proteins is driven by short amyloidogenic sequence domains within the protein full sequence that self-assemble into fibrils [21,22]. Amyloid formation was thought to be associated solely with amyloid diseases such as Alzheimer's and Parkinson's diseases [23-26]. However, numerous studies demonstrated that amyloids could also be exploited as promising bionanomaterials $[27,28]$ or even assume physiologically relevant roles $[29,30]$.

We previously demonstrated that the ultrashort and homologous peptide sequences GAITIG and GAIIG can spontaneously self-assemble into amyloid fibrils [31,32]. The GAITIG sequence is part of the adenovirus fiber shaft segment that, in the absence of its natural trimerization motif, aggregates into amyloid-type fibrils. By employing a reductionist approach, the sequence GAITIG was previously shown to be a minimal self-assembling building block [32,33]. Similarly, the sequence GAIIG, which is part of the amyloid- $\beta$ peptide (residues 29-33) and also part of the HIV-1 gp120 V3 loop (residues 24-28), can also spontaneously form a $\beta$-sheet amyloid core [31]. Exposed residues, outside the $\beta$-sheet GAITIG or GAIIG core, could be accessible and available for suitable selected modifications, rendering the resulting rationally designed sequences available for applications in biomedicine and technology [34,35]. Thus, both peptides were previously used as starting sequences for the computational and experimental design of functional scaffolds [34-36].

In the present study, we sought to rationally design self-assembling amyloid peptide sequences containing cationic residues conferring cell-penetrating properties and eventual DNA-binding ability. 
We employed computational methods, starting with scaffolds YATGAIIGNII and RGDSGAITIGC, and mutated key non- $\beta$-sheet positions at the termini of the scaffolds, namely, residues one, two, three, and eleven. We replaced these exposed residue positions with a combination of positively charged residues (Arg, and Lys) and tyrosine residues [37], to mimic the cell-penetrating properties and DNA-binding ability of CPPs. The computational and experimental studies of the two rationally designed amyloid peptides, KYKGAIIGNIK and KYRSGAITIGY (hereinafter referred to as KK and KY, respectively), directed us to three conclusions concerning their properties. Firstly, they can spontaneously self-assemble into amyloid fibrils; secondly, they can interact electrostatically with plasmid DNA to form complexes; thirdly, they can transfer plasmid DNA (pDNA) into mammalian cells and promote protein expression of the gene of interest. Moreover, the formulated peptide/DNA complexes exhibit long-term stability, with very limited cytotoxicity, and the cationic peptides display a strong bactericidal effect against Escherichia coli.

\section{Materials and Methods}

\subsection{Materials}

KYKGAIIGNIK and KYRSGAITIGY peptides were custom-synthesized by GenScript with C-terminal amidation. The purity of the peptides was over 95\%. The pGL3 plasmid with the SV40 promoter containing the gene for expressing luciferase was obtained from Addgene. The HEK293T cell line was cultured at $37^{\circ} \mathrm{C}, 5 \% \mathrm{CO}_{2}$ in DMEM (Gibco) supplemented with $10 \%$ fetal bovine serum (Gibco) and $50 \mu \mathrm{g} / \mathrm{mL}$ gentamycin. OPTI-MEM (Gibco) was used to obtain a reduced environment for the optimal transfection conditions. Thiazolyl blue tetrazolium bromide (MTT) and Congo red were purchased from Sigma-Aldrich. Quant-IT PicoGreen double-stranded DNA (dsDNA) assay kit was purchased from ThermoFisher Scientific. The Proteostat ${ }^{\circledR}$ aggresome detection kit was from Enzo.

\subsection{Computational Methods}

We used two separate approaches to rationally design and select two peptides with sequences $\mathrm{NH}_{3}{ }^{+}-\mathrm{KYRSGAITIGY-CONH}{ }_{2}$ and $\mathrm{NH}_{3}{ }^{+}-\mathrm{KYKGAIIGNIK-CONH}{ }_{2}$. Upon selection of the two peptide sequences, we computationally investigated the two designed peptides using replica exchange molecular dynamics (REMD) simulations. Firstly, we investigated the conformational properties of the isolated, individual designed peptides through infinite dilution REMD simulations. Then, we investigated the self-assembly properties of the designed peptides through finite dilution REMD simulations comprising copies of the designed peptides in a cubic box, per designed peptide. Using the structures extracted from the finite dilution simulations, we categorized the $\beta$-sheet structures formed by the designed peptides into two-, three-, four-, five-, and six-stranded antiparallel, parallel, or mixed $\beta$-sheet structures, identified the predominant configuration (parallel or antiparallel $\beta$-sheets) adopted by each of the two designed peptides, and identified the key $\beta$-sheet interactions formed within the self-assembled structures of the two designed peptides. Subsequently, we extracted the highly ordered and well-aligned $\beta$-sheet structures, investigated the key interactions formed between the amino acids within the structures, and calculated the solvent accessibility of the designed residues to assess the peptides' functionality. Below, we provide a detailed description of the computational methods employed to design and study the two peptides.

\subsection{Rational and Computational Design of the Positively Charged Peptides}

We aimed to design functional amyloid peptides with cell-penetrating and DNA-binding properties through two separate approaches.

In the first approach, we used the computationally elucidated structures of elementary $\beta$-sheet structural units formed by the amyloid designable scaffold, RGDSGAITIGC [36], as input flexible structural templates to an in-house optimization-based model, which was previously used for the design of functional amyloid materials [34,38]. According to our previous study, the dominant 
configuration of the $\beta$-sheet structures formed by peptide RGDSGAITIGC is antiparallel, and residue positions one, two, three, and eleven are amenable for modification as they are not part of the $\beta$-sheet core [36]. In the current study, we used the antiparallel elementary $\beta$-sheet structural units formed by

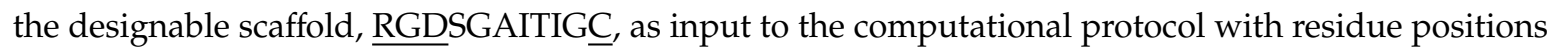
one, two, three, and eleven as designable positions (underlined). The computational design model was performed without subjecting the optimization-based model any constraints related to the binding to a specific ion (e.g., materialphore model related constraints as in Reference [34]). Upon solution of the model, a total of $20^{4}$ sets of mutations were evaluated and ranked according to the energy defined in the objective function. Subsequently, for the post-design constraints, we hypothesized that a combination of positively charged residues (Arg and Lys) and tyrosine residues at the designable positions would be desirable as (i) positively charged residues are known to penetrate cell membranes [39], and (ii) aromatic residues in the order $\mathrm{Y}>\mathrm{W}>\mathrm{F}$ are abundant in proteins interacting with DNA [37]. To introduce cell-penetrating motifs at the N-terminal of the designed sequence, we performed a bioinformatics analysis on the motifs with sequence XXXS, where XXX corresponds to any residues within designable positions one, two, and three, and $S$ corresponds to serine, in cell-penetrating peptides deposited in the Database of Cell-Penetrating Peptides (CPPsite2.0 [40]). From the bioinformatics search, we observed that only RYYS and KYRS sequence motifs occurred as a part of any cell-penetrating peptides. We selected the sequence motif KYRS as we considered that tyrosine at position 3 in the motif RYYS could extend the $\beta$-sheet core, probably negatively affecting its functional properties. After imposing the above post-design constraints, the top-ranked designed peptide was the peptide KYRSGAITIGY; thus, we selected the designed peptide with sequence KYRSGAITIGY for further investigation. It is worth noting that the selected designed peptide sequence was among the top $10 \%$ of all $20^{4}$ possible sequences according to the energy ranking defined in the objective function prior to the introduction of any constraints.

In the second approach, we aimed to rationally design a functional amyloid peptide with cell-penetrating and DNA-binding properties using the amyloid designable scaffold, YATGAIIGNII [31], as a basis. As, according to our previous study [31], residue positions one, two, three, and eleven are amenable for modification as they are not part of the $\beta$-sheet core, we rationally designed peptide sequences by introducing mutations to the designable (underlined) positions of YATGAIIGNII. Similarly to the rational design described above, we performed a bioinformatics analysis for sequence motifs containing positively charged residues or tyrosines within cell-penetrating peptides deposited in CPPsite2.0 [40]. In the analysis, we disallowed tyrosine at position three to avoid the extension of the $\beta$-sheet core of the self-assembled designed peptides. Based on the bioinformatics analysis, the motifs KYK, KYR, RYK, and RYR were possible amino-acid replacements at the designable positions one, two, and three with the motif KYK occurring most frequently. Thus, we mutated the residue positions one, two, and three to lysine, tyrosine, and lysine, respectively. In contrast to the computational design model described above in the first approach, in this approach, motivated by the fact that positively charged residues are beneficial for both cell penetration and DNA binding functionality, we rationally substituted position eleven with lysine. Thus, the aforementioned direction resulted in the designed peptide KYKGAIIGNIK, and we selected the designed peptide for further investigation.

One of the designed peptides was engineered on the basis of $\mathrm{NH}_{3}{ }^{+}-\mathrm{RGDSGAITIGC}-\mathrm{CONH}$. For the current study, we investigated both designed peptides with the same $\mathrm{NH}_{3}{ }^{+}-$and $-\mathrm{CONH}_{2}$ terminal ends; we considered that the positive charge of the $\mathrm{NH}_{3}{ }^{+}$-terminal end could additionally be favorable for the desired DNA-binding and cell-penetrating functional properties of the amyloid materials formed by the designed peptides. Thus, the selected designed peptides with sequence $\mathrm{NH}_{3}{ }^{+}-\mathrm{KYRSGAITIGY}-\mathrm{CONH}_{2}$ and $\mathrm{NH}_{3}{ }^{+}-\mathrm{KYKGAIIGNIK}-\mathrm{CONH}_{2}$ were subsequently investigated using infinite and finite dilution simulations, independently, following a protocol developed by Tamamis and Archontis [41], which was initially executed for the study of peptides with sequence NSGAITIG [33], LSFDNSGAITIG [42], and LSGSDSDTLTV [43], and was later widely used by our group 
to shed light onto the amyloid self-assembly properties of short peptides [31,34,36,38], as described in the sections below.

\subsection{Infinite Dilution Simulations Investigating the Peptides' Conformational Properties}

We performed infinite dilution simulations of two peptides with sequence KYRSGAITIGY and KYKGAIIGNIK in aqueous solution, independently, using REMD simulations [33,44-49] in CHARMM [50]. The REMD simulations consisted of eight replicas with temperatures 283, 300, 318, $336,356,377,403$, and $432 \mathrm{~K}$. The temperatures were selected such that the average exchange rates between the different replicas were $27 \% \pm 1 \%$ and $28 \% \pm 2 \%$ for KYRSGAITIGY and KYKGAIIGNIK, respectively, in line with References [33,41]. The initial structures of the peptides corresponded to linear structures build in CHARMM [50]. The peptides were modeled using the CHARMM19 force field [51], and the aqueous environment was modeled using the FACTS19 [52] implicit solvent model with the surface tension coefficient set to $0.015 \mathrm{kcal} \cdot \mathrm{mol}^{-1} \cdot \AA^{-2}[31,34,36]$. For all simulations, we used Langevin dynamics with a friction coefficient of $5 \mathrm{ps}^{-1}$ introduced on all heavy atoms and simulation snapshots extracted in 100-ps intervals. The duration of each simulation per temperature was $150 \mathrm{~ns}$ for both peptides, independently, for an aggregate total simulation duration of $1.2 \mu$ s per peptide. Upon completion of the infinite dilution simulations, we extracted the 15,000 simulation snapshots of the 300-K trajectory. We subsequently performed a root-mean-squared deviation (RMSD)-based clustering analysis on the extracted snapshots using Wordom [53,54] and selected representative conformations from the six most populated clusters for each peptide resulting in six conformations per peptide. The clustering analysis was performed based on the backbone atoms of the peptides using a clustering radius of $2 \AA$ and the quality-clustering algorithm. The six extracted conformations per peptide corresponded to the centers, or most representative structure, of each cluster, and they were used as initial structures in the finite dilution REMD simulations investigating the peptides' self-assembly properties described in the latter section. All six extracted conformations were distinct from the initial extended structures of the two peptides used for the REMD simulations; the RMSDs of the extracted structures of KYRSGAITIGY and KYKGAIIGNIK ranged from 7.4 to $10.6 \AA$ and 7.4 to $8.4 \AA$, respectively.

\subsection{Finite Dilution Simulations Investigating the Peptides' Self-Assembly Properties}

We performed independent REMD simulations in CHARMM [50] for both designed peptides to investigate their self-assembly properties, analogously to References [31,33,36,38,41,43]. The simulation system corresponded to six copies of the peptide KYRSGAITIGY in a $157-\AA$ cubic periodic box and KYKGAIIGNIK in a 154-Å cubic periodic box, resulting in an approximately $3 \mathrm{mg} / \mathrm{mL}$ concentration for the two simulation systems. The initial conformations of the six peptide copies were obtained from the six conformations extracted from the corresponding aforementioned finite dilution REMD simulations. For each of the two simulations, all six copies of the peptide were initially placed in the center of the cubic periodic box, and then translated by $+25 \AA$ in the $x$-direction, $-25 \AA$ in the $x$-direction, $+25 \AA$ in the $y$-direction, $-25 \AA$ in the $y$-direction, $+25 \AA$ in the $z$-direction, or $-25 \AA$ in the $z$-direction such that a peptide was placed at the center of each face of a $50-\AA$ cubic box. The REMD simulations consisted of 16 replicas with temperatures of 290, 295, 300, 310, 305, 315, $321,327,333,339,345,352,359,366,373$, and $380 \mathrm{~K}$. The temperatures were selected such that the average exchange rates between the different replicas were $29 \% \pm 2 \%$ and $29 \% \pm 2 \%$ for KYRSGAITIGY and KYKGAIIGNIK, respectively, in line with References [33,41]. The simulations were performed using the CHARMM19 force field [51] and the FACTS19 implicit solvent model [52] with the surface tension coefficient set to $0.015 \mathrm{kcal} \cdot \mathrm{mol}^{-1} \cdot \AA^{-2}[31,36,38]$, with simulation snapshots extracted in 10-ps intervals. For all simulations, we used Langevin dynamics with a friction coefficient of $5 \mathrm{ps}^{-1}$ on all heavy atoms. The duration of each simulation per temperature was $1.000 \mathrm{~ns}$ for both peptides, independently, for an aggregate total simulation duration of $16 \mu$ s per peptide. Upon completion of 
the finite dilution simulations, we extracted the 100,000 simulation snapshots of the $300-\mathrm{K}$ trajectory for each peptide independently.

\subsection{Categorization of $\beta$-Sheet Structures and Key $\beta$-Sheet Interactions.}

We identified the formation of intermolecular $\beta$-sheet structures and categorized the intermolecular $\beta$-sheet patterns into antiparallel, parallel, or mixed two-, three-, four-, five-, and six- stranded $\beta$-sheet structures, similarly to References [31,36,38] for designed peptides KYRSGAITIGY and KYKGAIIGNIK. The intermolecular $\beta$-sheet structures were identified using DSSP [55] and categorized using in-house FORTRAN programs. We calculated the (\%) moving average number of structures containing antiparallel, parallel, or mixed $\beta$-sheet structures in each of the two-, three-, four-, five-, and six- stranded peptides as shown in Figure 1. For both designed peptides, the analysis showed that the peptides preferentially formed antiparallel $\beta$-sheet structures over parallel $\beta$-sheet structures. Following this analysis, we focused our further analysis on four-, five-, and six-stranded antiparallel $\beta$-sheet structures, which we considered more complex compared to two- and three-stranded $\beta$-sheets $[31,33,36,38,41,43]$. Thus, we extracted the four-, five-, and six-stranded antiparallel $\beta$-sheet structures from each of the simulation trajectories corresponding to the two designed peptides and calculated the (\%) probability of a pair of residues belonging to separate adjacent peptides to be involved in a $\beta$-bridge conformation. From this analysis, we identified the predominant configuration (parallel or antiparallel) and key patterns of $\beta$-sheet interactions, which indicated the key amyloidogenic regions of each designed peptide, as shown in Figure 2. The specific analysis, in addition, also identified if the designed residues predominantly participated in the $\beta$-sheet interactions, which would hinder their availability for functionality. 
A

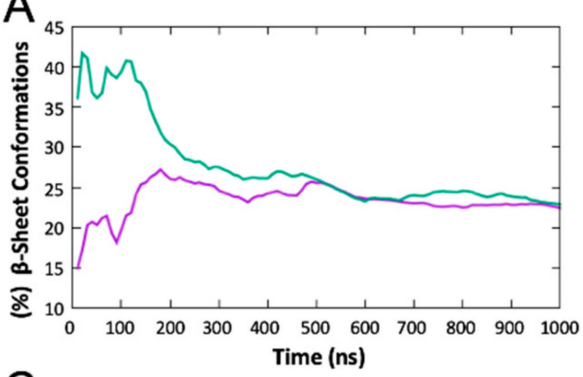

C

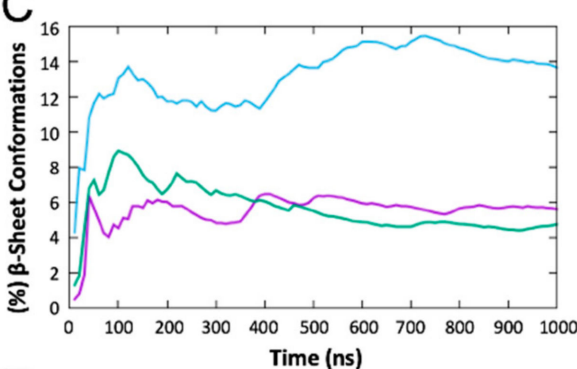

E

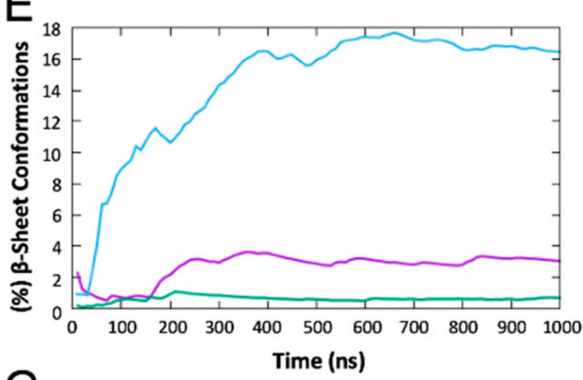

G

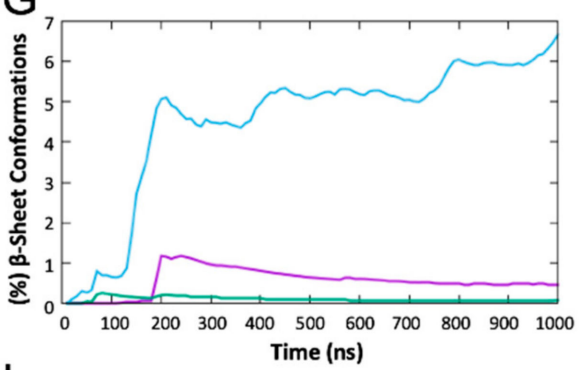

I

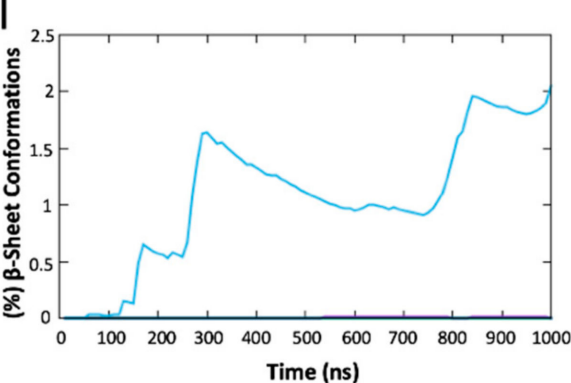

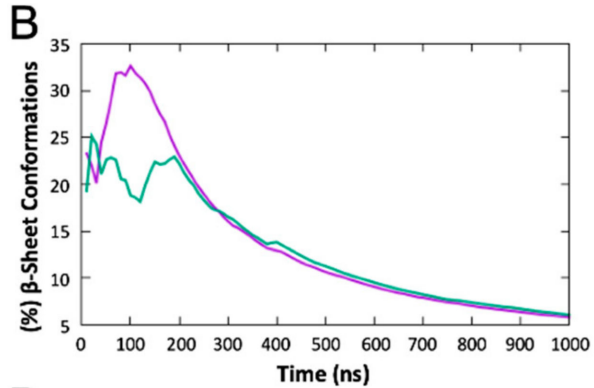

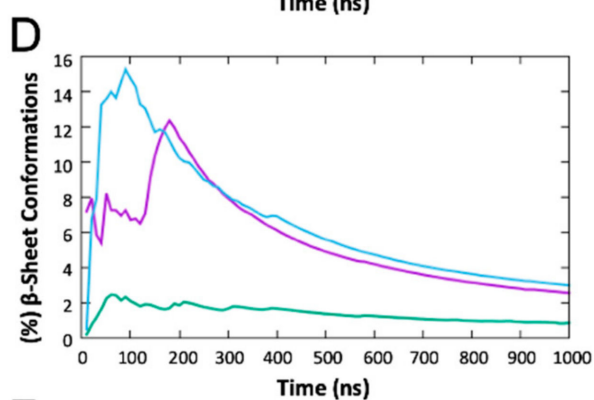

$\mathrm{F}$
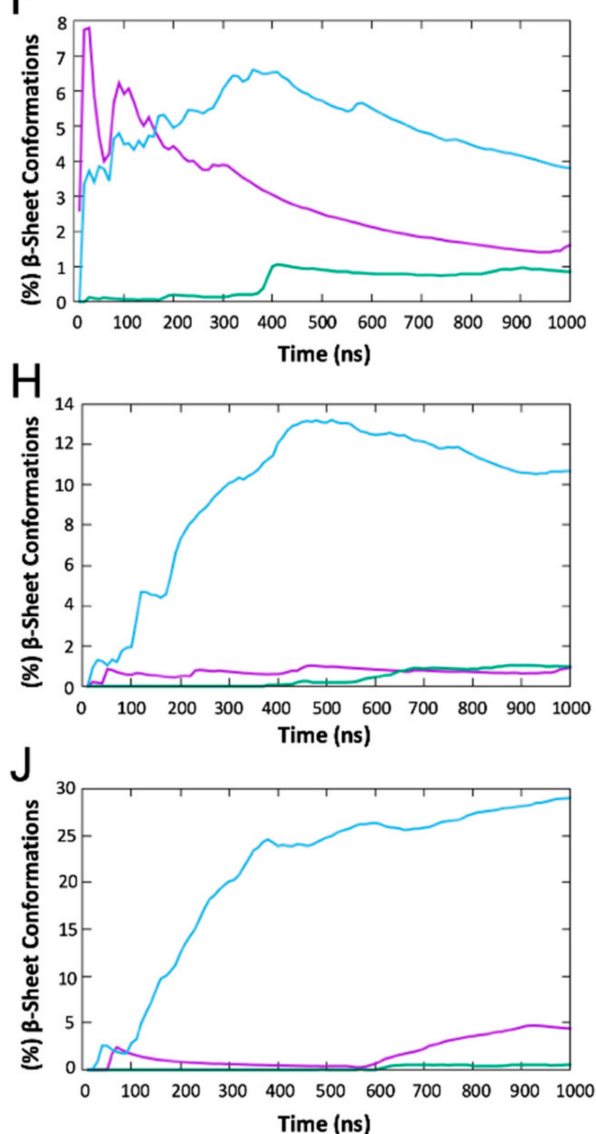

Figure 1. Moving averages of the fraction (\%) of conformations with intermolecular $\beta$-sheets ( $Y$-axis) in the replica exchange molecular dynamics (REMD) simulations at $300 \mathrm{~K}$ with respect to time ( $\mathrm{X}$-axis) for KYRSGAITIGY and KYKGAIIGNIK. Panels (A,C,E,G,I) correspond to two-, three-, four-, five-, and six-stranded $\beta$-sheets of peptide KYRSGAITIGY, respectively. Panels $(\mathbf{B}, \mathbf{D}, \mathbf{F}, \mathbf{H}, \mathbf{J})$ correspond to two-, three-, four-, five-, and six-stranded $\beta$-sheets of peptide KYKGAIIGNIK, respectively. Purple corresponds to antiparallel $\beta$-sheets, green corresponds to parallel $\beta$-sheets, and blue corresponds to mixed $\beta$-sheets. 
A

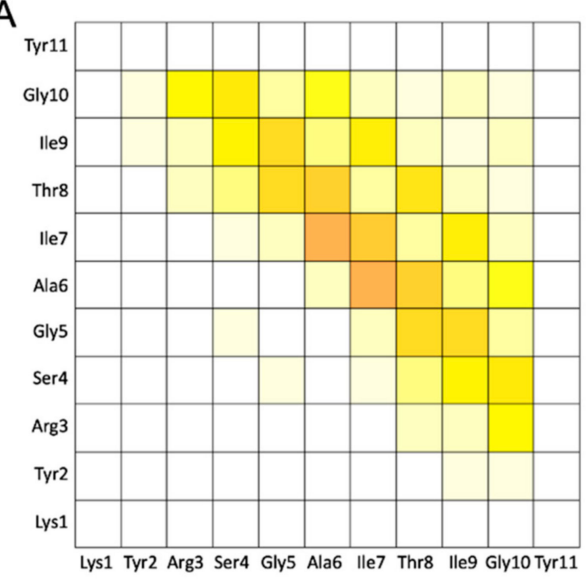

C

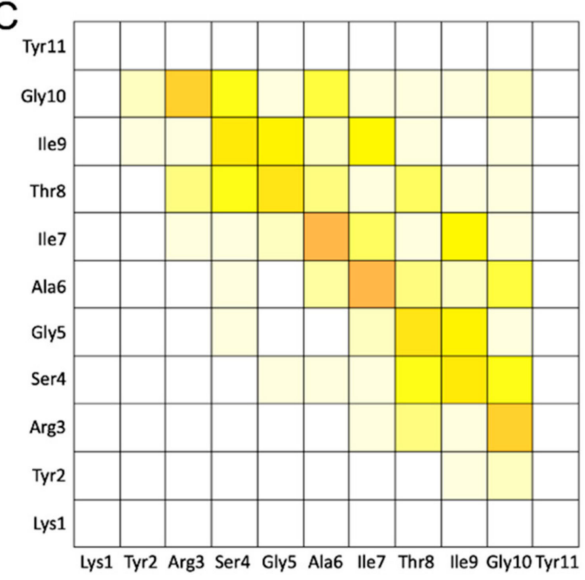

$\mathrm{E}$

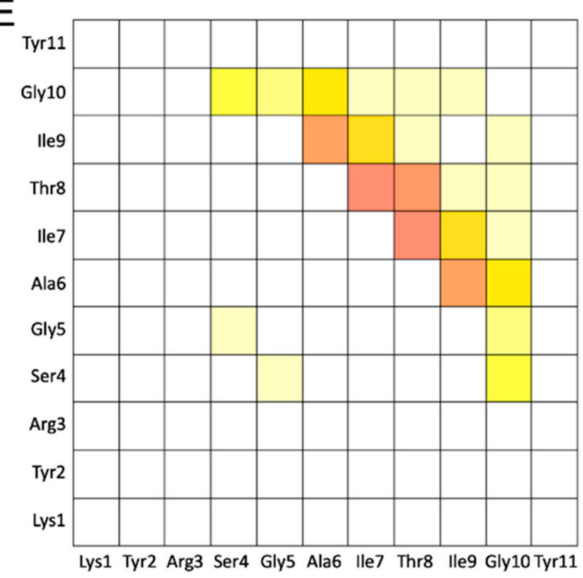

B

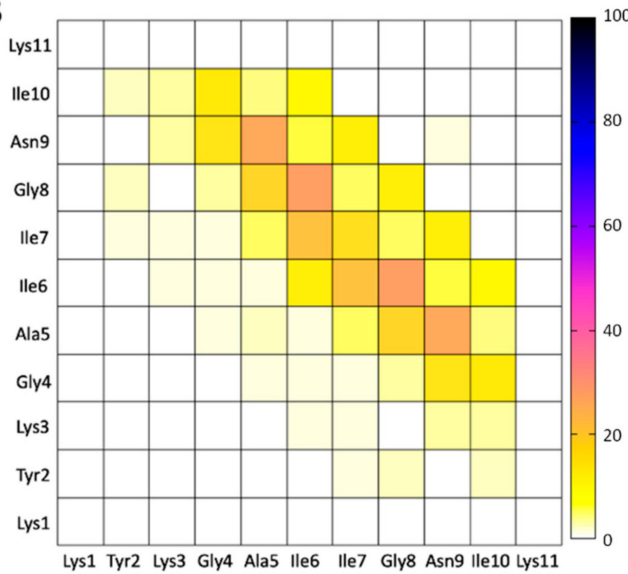

D

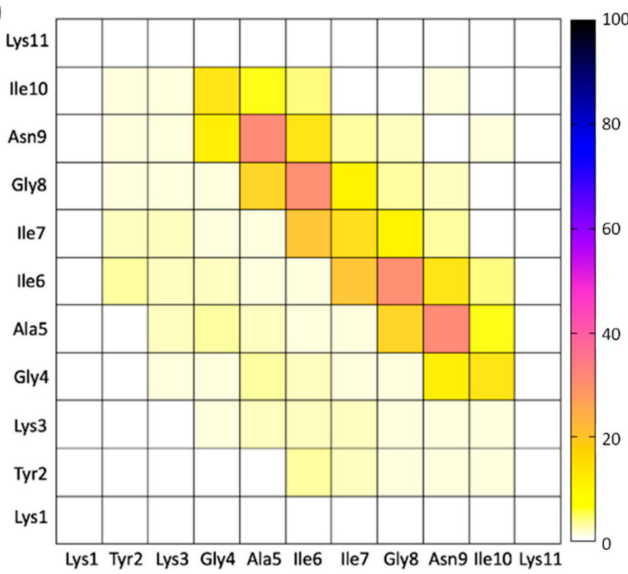

$\mathrm{F}$

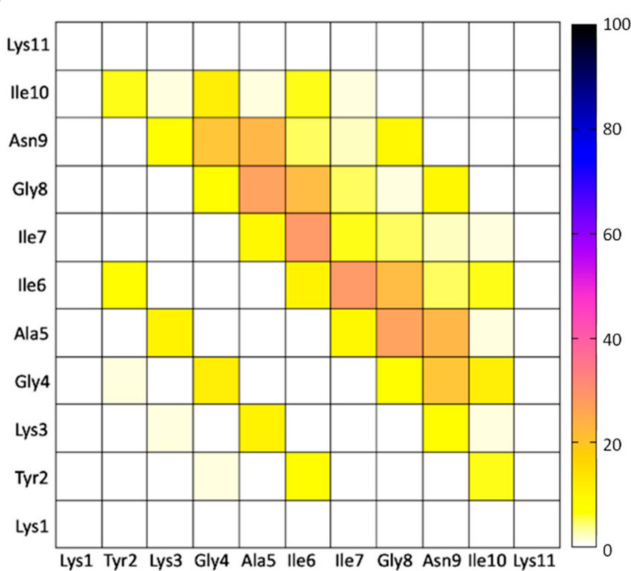

Figure 2. Density (\%) maps of residue pairs forming intermolecular $\beta$-bridges for KYRSGAITIGY and KYKGAIIGNIK. The pairs of residues belong to nearest neighboring peptides participating in an isolated $\beta$-bridge or extended $\beta$-sheet conformation in the REMD simulations at $300 \mathrm{~K}$. Panels $(\mathbf{A}, \mathbf{C}, \mathbf{E})$ correspond to four-, five-, and six-stranded antiparallel configurations of peptide KYRSGAITIGY, respectively. Panels (B,D,F) correspond to four-, five-, and six-stranded antiparallel configurations of peptide KYKGAIIGNIK, respectively.

2.7. Identification of Well-Aligned and Highly Ordered $\beta$-Sheet Conformation Using Polar $\left(P_{1}\right)$ and Nematic $\left(P_{2}\right)$ Order Parameters

We assessed the extent of peptide alignment and relative orientation of the individual peptides within the four-, five-, and six-stranded antiparallel $\beta$-sheet structures using the polar-order $P_{1}$ and 
nematic-order $P_{2}$ parameters, calculated through Wordom $[53,54]$. These parameters are used in the structural characterization of liquid crystals, and they were employed successfully in simulation studies of peptide aggregation [33,41-43,56,57]. The analysis was performed in line with References [31,33,36, $38,41,43]$ with the unit vector $\vec{z}_{i}$, defined as the segment spanning from the C $\alpha$ atom of residue four to the $\mathrm{C} \alpha$ atom of residue nine. The analysis was focused on four-, five-, and six-stranded $\beta$-sheet structures as they have higher complexity than two- and three-stranded $\beta$-sheets; thus, the structural patterns observed in the former can potentially correspond to patterns that may exist in naturally occurring fibrils formed by the peptides. According to the computed $\mathrm{P}_{1}$ and $\mathrm{P}_{2}$ parameters, among the four-, five-, and six-stranded antiparallel $\beta$-sheet structures, highly populated and highly ordered $\beta$-sheet structures were observed only in the four-stranded antiparallel $\beta$-sheet structures for both peptide systems. This can be attributed to the limited number of peptides within the finite dilution self-assembly simulations. Thus, as four-stranded $\beta$-sheets are complex enough to correspond to elementary $\beta$-sheet structural units and are present within a sufficient number of simulation snapshots for statistical analysis, we focused our analysis on four-stranded antiparallel $\beta$-sheet structures formed by the two designed peptides and constructed free-energy landscapes (Figure 3A,B) for each peptide system using two-dimensional probability $P\left(P_{1}, P_{2}\right)$ and Equation (1).

$$
G\left(P_{1}, P_{2}\right)=-k_{B} T \ln \left[P\left(P_{1}, P_{2}\right)\right]
$$

From the free-energy basins within the free-energy landscapes, we extracted the highly ordered and well-aligned $\beta$-sheet structures for each peptide system. Representative structures of highly ordered and well-aligned antiparallel $\beta$-sheet structures of KYRSGAITIGY and KYKGAIIGNIK are shown in Figure 3C,D, respectively.

Given that simulations are used with the expectation of reproducing experimental structures and dynamics, the reaction coordinates used for the construction of free-energy landscapes [58], in tandem with the choice of simulation scheme and solvent, are crucial. Regarding the former, the individual and combined uses of $P_{1}$ and $P_{2}$ parameters as reaction coordinates in free-energy landscapes to study conformations of amyloid peptides, to the best of our knowledge, were first carried out by Cecchini et al. [56] and Tamamis et al. [33] respectively. These parameters were shown to constitute effective reaction coordinates to construct free-energy landscapes through which the most highly ordered and well-aligned $\beta$-sheet conformations of amyloid peptides can be extracted from the simulations [31,33,34,36,38,41,43]. At the same time, such free-energy landscapes are valuable given that simulations can efficiently capture the conformational space of the simulated peptides. For this purpose, regarding the latter, we used REMD simulations [44-49] coupled with implicit solvation provided through FACTS19 [52]. The coordinate exchange achieved through a Metropolis criterion in REMD simulations allows low-temperature replicas to escape local minima and to borrow the sampling efficiency of high-temperature replicas, while it ensures that energetically inaccessible conformations (at a given temperature) are not allowed, and that all replicas gain access to conformations with the proper thermodynamic weight [41]. In addition, and most importantly for studies involving peptide self-assembly, the high-temperature runs permit the frequent dissolution and re-organization of aggregates and the sampling of a wide variety of intermolecular structures [41]. This is an essential feature of the REMD simulations, which a traditional run at room temperature would lack [41]. Specifically, in this study, the following temperatures were used: 290, 295, 300, 305, 310, $315,321,327,333,339,345,352,359,366,373$, and $380 \mathrm{~K}$, which in both simulated systems allowed a highly uniform exchange probability of $29 \% \pm 2 \%$ [41], as mentioned above. The fairly constant and relatively high exchange rate throughout the temperature space was considered important for observed aggregates at the experimental temperature to be relatively stable, to enable the exploration of intermolecular structures involving several peptides, and also allow the aggregates to undergo sufficient re-organization at higher temperatures [41]. The relatively high exchange rate was especially considered beneficial for replicas to execute random walks covering the entire temperature space [41]. 
In conjunction with the REMD simulation scheme, the use of implicit solvation, specifically FACTS19, which was used extensively in several studies [31-34,36,38,41-43,59-62], can significantly lower the computational cost and accelerate peptide conformational transitions, while simultaneously providing a compromise between accuracy and efficiency [41]. Nevertheless, the choice of an implicit solvent model needs to be conducted with caution, and it should be verified either with respect to explicit solvent results and/or with respect to experimental studies [41].

A
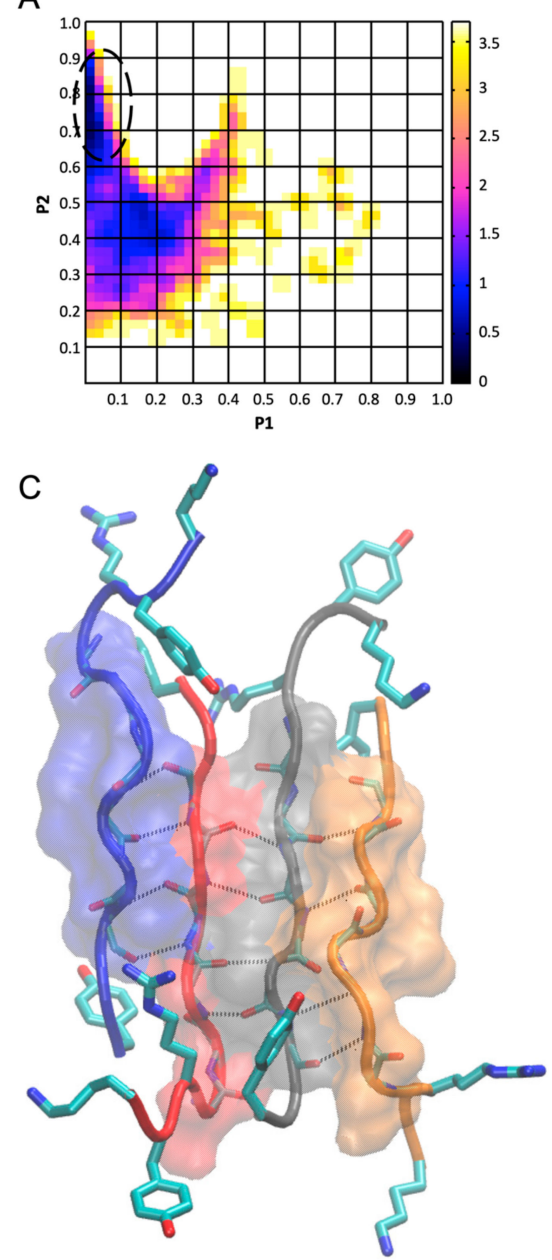

B
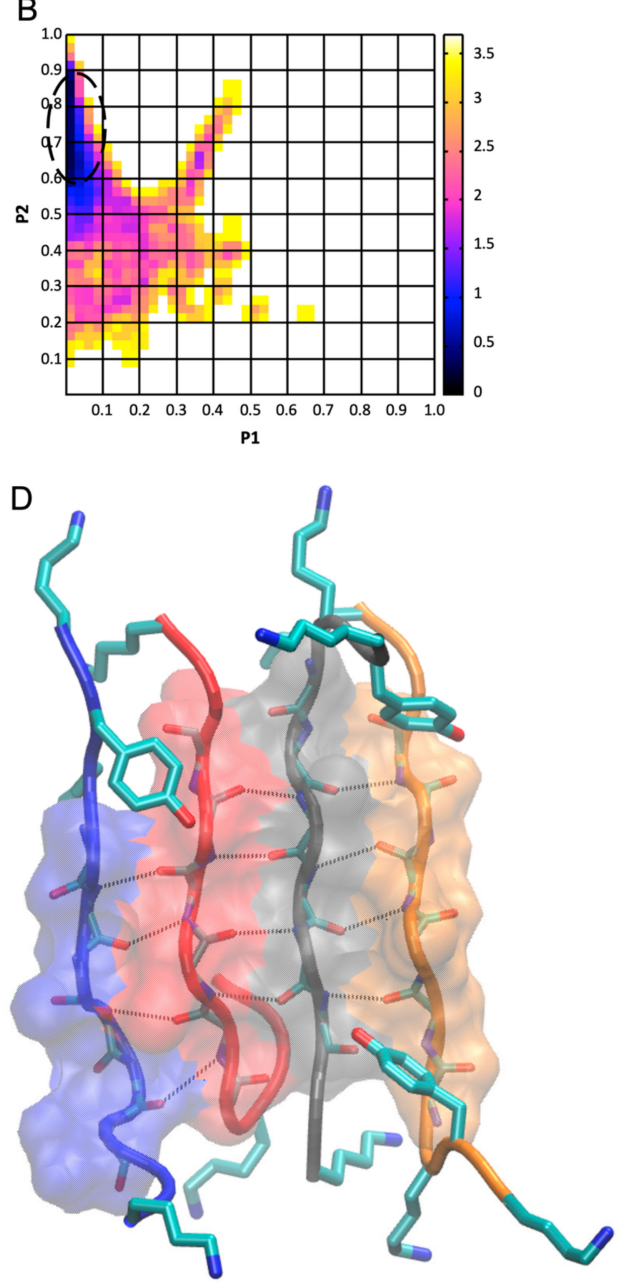

Figure 3. Free-energy surfaces constructed from the two-dimensional (2D) probabilities of order parameters $P_{1}$ and $P_{2}$ and molecular graphics images of representative structures of KYRSGAITIGY and KYKGAIIGNIK extracted from the free-energy minima. Panels $(\mathbf{A}, \mathbf{B})$ correspond to free-energy surfaces constructed from the $2 \mathrm{D}$ probabilities of order parameters $P_{1}$ and $P_{2}$, calculated using the four-stranded antiparallel $\beta$-sheets formed by KYRSGAITIGY (KY) and KYKGAIIGNIK (KK), respectively, observed in the replica exchange MD simulations at $300 \mathrm{~K}$. The global free-energy minima in the plots are located in basins which are marked using black dashed lines, and, within these, we observe the presence of highly ordered and well-aligned $\beta$-sheet conformations. Panels $(\mathbf{C}, \mathbf{D})$ correspond to molecular graphic images of representative highly ordered and well-aligned conformations of peptides KYRSGAITIGY and KYKGAIIGNIK in antiparallel arrangement, respectively. The peptide backbone is shown in tube representation, and the backbone atoms forming $\beta$-bridges are shown in thin licorice representation and are colored by name, while the $\beta$-bridge-associated hydrogen bonds are shown using black dashed lines. The peptides are colored in blue, red, gray, and orange from left to right. Residue moieties 4-9 in each of the two designed peptides form amyloid zipper-like patterns and are shown in transparent surface representation. Side-chain atoms of residues at positions one, two, three, and eleven are shown in thick licorice representation. 


\subsection{Determination of Exposure of Designed Residues}

We determined the solvent accessibility of the designed residues to assess their exposure and their potential functionality. The degree of solvent accessibility of residues at positions one, two, three, and eleven within the extracted highly ordered and well-aligned four-stranded antiparallel $\beta$-sheet structures for both designed peptides, KYRSGAITIGY and KYKGAIIGNIK, was determined using Wordom [53,54]. Similarly to References [34,36], we calculated the solvent accessible surface area, i.e., the total accessible surface area ratio of residues at positions one, two, three, and eleven of the two central peptides in each highly ordered and well-aligned four-stranded antiparallel $\beta$-sheet structures. As the degree of solvent accessibility of the two outer peptides was artificially high due to the absence of interacting peptides on both sides, their values were not considered in the analysis. The total accessible surface areas were defined as the maximum solvent accessible surface area (SASA), which was the SASA of the set of residues with all other atoms removed, as in References [34,36].

\subsection{Amyloid Fibril Formation}

Peptide powders were dissolved in sterile filtered double-distilled water in a final concentration of $6 \mathrm{mg} / \mathrm{mL}$. The resulting peptide solutions were incubated at room temperature for three days. Formation of fibrils was confirmed by field-emission SEM (FE-SEM), TEM, and Congo red staining as previously described [36].

\subsection{Field-Emission Scanning Electron Microscopy (FE-SEM)}

After the three-day incubation period, $10 \mu \mathrm{L}$ of each peptide sample, diluted 1:6, was deposited on a cover glass and was air-dried overnight. Dried samples were covered with $10 \mathrm{~nm}$ of $\mathrm{Au} / \mathrm{Pd}$ sputtering. Observation experiments were performed using a JEOL JSM-7000F microscope operating at $15 \mathrm{kV}$.

\subsection{Transmission Electron Microscopy (TEM)}

Each sample $(5 \mu \mathrm{L})$ was deposited directly onto a formvar/carbon-coated electron microscopy grid for $2 \mathrm{~min}$. Excess was carefully removed with a filter paper, and the sample was stained with $2 \%$ $w / v$ uranyl acetate for $2 \mathrm{~min}$. The observations were conducted with a JEOL JEM-2100 transmission electron microscope at $80 \mathrm{kV}$.

\subsection{Congo Red Staining}

Each peptide solution $(20 \mu \mathrm{L})$ was thoroughly mixed with $5 \mu \mathrm{L}$ of a fresh Congo red assay solution (10 mM Congo Red, $2.5 \mathrm{mM} \mathrm{NaOH}$ in 50\% ethanol). A drop of the mixture was deposited onto a glass coverslip and was examined before or after drying at room temperature, with a Zeiss Stemi 2000-C microscope with and without the use of a crossed polarizer.

\subsection{Formulation of Cationic Peptides and $p D N A$ Complexes}

The pGL3-SV40 luciferase-expressing plasmid was mixed with the self-assembled peptides at various ratios, in a total volume of $50 \mu \mathrm{L}$ of double-distilled sterile water. Formulations were allowed to assemble for at least $1 \mathrm{~h}$ in room temperature before cell transfection.

\subsection{Gel Retardation Assay}

The formation and DNA condensation of the CPP-DNA complexes was verified by electrophoresis on a $0.5 \%$ agarose gel in TAE (Tris Acetate-EDTA) $1 \times$ buffer and imaged by staining of the gel with Gel-Red (Biotium). Complexes were formed as previously described. Firstly, $0.5 \mu \mathrm{g}$ of pGL3-SV40 was mixed with $10,25,50,100$, or $200 \mu \mathrm{g}$ of each peptide for $1 \mathrm{~h}$. Then, $4 \mu \mathrm{L}$ of loading buffer was mixed with the samples before the electrophoresis. 


\subsection{PicoGreen Fluorescence Quenching Experiments}

The pDNA $(0.5 \mu \mathrm{g})$ was labeled with $30 \mu \mathrm{L}$ of the PicoGreen reagent $(1: 150 w / v)$ in TE (Tris-EDTA) buffer for $30 \mathrm{~min}$ at room temperature. The labelled pDNA was mixed with 10, 25, 50, 100, and $200 \mu \mathrm{g}$ of the self-assembled peptides for $1 \mathrm{~h}$ at room temperature. PicoGreen binds to the grooves of the DNA backbone and strongly fluoresces when excited at $488 \mathrm{~nm}$. Quenching of the fluorescence indicates packaging of the nucleic acid. The quenched fluorescence was analyzed in a BioRad CFX Connect Real-Time System, and the naked pDNA labeled with the PicoGreen fluorescence signal was used to normalize the signal detected from the peptide-DNA signal. Values were expressed as quenching percentage.

\subsection{Zeta Potential Measurement}

The pDNA-peptide complexes were formulated in a final volume of $200 \mu \mathrm{L}$ of filtered double-distilled water in different DNA-peptide concentration ratios (1:312, 1:625, 1:1250, 1:2500, and 1:5000). An additional dilution with $1 \mathrm{mM} \mathrm{NaCl}$ to up to a 1-mL volume followed before measurement. Measurements were performed in a ZetaSizer Malvern instrument, using the Smoluchowski model, set to a number of five runs.

\subsection{Cell Internalization of the Amyloid-Forming Peptides}

Firstly, $5 \times 10^{4}$ HEK293T human embryonic kidney cells were seeded for $24 \mathrm{~h}$ in a 24-well plate after addition of a 13-mm Tissue Culture coverslip at the bottom of the well. The culture medium (DMEM) was replaced, and $25 \mu \mathrm{g}$ of the fibrillar peptide sequence, diluted in $0.5 \mathrm{~mL}$ of DMEM, was added for overnight incubation. the culture media were aspirated, and the cells were carefully washed two times with PBS $1 \times$. The cells were fixed with $4 \%$ formaldehyde for $30 \mathrm{~min}$, washed with PBS $1 \times$, and permeabilized for 5 min with $0.5 \%$ Triton X-100, 3 mm EDTA, pH 8. After washing twice with PBS $1 \times$, the cells were treated with the staining solution containing the Proteostat ${ }^{\circledR}$ aggresome staining and Hoechst nuclear dye. Additional washes with PBS $1 \times$ followed, the coverslip was mounted on a microscope coverslip, and the internalization efficacy of the peptides was assessed in a Leica SP8 inverted confocal microscope at excitation/emission 500/600 nm for the Proteostat ${ }^{\circledR}$ dye and excitation/emission 350/461 nm for Hoechst 33342.

\subsection{MTT Cell Proliferation Assay}

Cell viability in the presence of the peptides was studied by monitoring the conversion of thiazolyl blue tetrazolium bromide reagent (MTT) into formazan by the mitochondrial dehydrogenases of the living cells. HEK293T cells with concentrations of $7 \times 10^{3}$ cells/well were cultured in a 96-well plate for $24 \mathrm{~h}$. Removal of the medium was followed by treatment of the cells with increasing concentrations $(10,25,50,100,200 \mu \mathrm{g})$ of the self-assembled peptide, suspended in a total volume of $200 \mu \mathrm{L}$ of culture medium. Cells that were not treated with the peptide served as control. After an incubation period of $48 \mathrm{~h}$, the medium was carefully removed and replaced with $100 \mu \mathrm{L}$ of fresh medium and $10 \mu \mathrm{L}$ of MTT $(5 \mathrm{mg} / \mathrm{mL})$ dissolved in PBS $1 \times$. The cells were incubated for $4 \mathrm{~h}$ to allow the development of the purple formazan products and the MTT/culture medium was substituted with $100 \mu \mathrm{L}$ of an isopropanol-DMSO 1:1 solution. The formazan crystals were allowed to dissolve for $15 \mathrm{~min}$ at $37^{\circ} \mathrm{C}$. The absorbance was measured at $570 \mathrm{~nm}$ in a Synergy HTX BioTEK Plate Reader.

\subsection{Plasmid Transfection and Luciferase Assay}

HEK293T cells were seeded in a 24-well plate at a density of $6 \times 10^{4}$ cells per well and grown until $60 \%$ confluency. The cultured medium was smoothly removed, and $500 \mu \mathrm{L}$ of OPTI-MEM medium containing $50 \mu \mathrm{L}$ of the preformed pDNA-peptide complexes in ratios $(1: 312,1: 625,1: 1250,1: 2500$, and 1:5000 after sequential dilutions) were carefully added into the wells. After a 4-h incubation period at $37^{\circ} \mathrm{C}$, the medium was removed, $1 \mathrm{~mL}$ of fresh DMEM supplemented with FBS and 
gentamycin was added, and the cells were incubated for $48 \mathrm{~h}$ to allow for reporter gene expression. Luciferase activity was measured by using a luciferase assay system according to the manufacturer's guidelines (Bright-Glo, Promega, Madison, WI, USA) in a Synergy HTX BioTEK Plate Reader. Protein concentration in cell lysates was assessed by the Bradford assay.

\subsection{Antimicrobial Testing}

The antimicrobial activity of the peptides was assessed by following the broth microdilution method [63] adjusted to the guidelines of CLSI (Clinical and Laboratory Standards Institute. Performance standards for antimicrobial susceptibility testing; 16th informational supplement. CLSI document M100-S16CLSI, Wayne, PA (2006)) and EUCAST (European Committee for Antimicrobial Susceptibility Testing) of the European Society of Clinical Microbiology and Infectious Diseases (ESCMID). Bacteria were grown in Luria Bertani broth (LB) in a shaking incubator at $37^{\circ} \mathrm{C}$ overnight, using individual colonies retrieved from a fresh overnight BL21 DE3 plate. The bacterial suspension was adjusted to $10^{6} \mathrm{CFU} / \mathrm{mL}$ in LB according to the MacFarlane standard. Then, $50 \mu \mathrm{L}$ of the bacterial inoculum was mixed in 96-well plates with the twofold diluted peptide solutions (50 $\mu \mathrm{L})$ to reach final concentrations of peptides ranging from $0.75 \mathrm{mg} / \mathrm{mL}$ to $0.005 \mathrm{mg} / \mathrm{mL}$, including two inhibition controls (kanamycin $50 \mu \mathrm{g} / \mathrm{mL}$ and ampicillin $100 \mu \mathrm{g} / \mathrm{mL}$ ), a sterility control, and a growth control. Each peptide concentration was tested in triplicate. The plate was incubated for $24 \mathrm{~h}$ at $37^{\circ} \mathrm{C}$, and the optical density was measured at $600 \mathrm{~nm}\left(\mathrm{OD}_{600}\right)$ in a Synergy HTX BioTEK Plate Reader.

\subsection{1. $p D N A$ Internalization and Sub-Cellular Localization}

Firstly, $7 \times 10^{4}$ HEK293T human embryonic kidney cells were seeded for $24 \mathrm{~h}$ in a 24 -well plate after addition of a 13-mm TC Coverslip at the bottom of the well. The following day, $50 \mathrm{ng}$ of pGL3-SV40 plasmid was incubated for 30 min with the PicoGreen dye (1:150 dilution), and it was further mixed with $250 \mu \mathrm{g}$ of the KK or KY peptide for $1 \mathrm{~h}$. The medium was carefully removed, and $50 \mu \mathrm{L}$ of the pre-stained pGL3-SV40-peptide complex diluted in $500 \mu \mathrm{L}$ of OPTI-MEM was added to the well. After a 4-h incubation period at $37^{\circ} \mathrm{C}$, the culture media were aspirated, and the cells were carefully washed two times with PBS $1 \times$. The cells were fixed with $4 \%$ formaldehyde for $15 \mathrm{~min}$, washed with PBS $1 \times$, and permeabilized for 5 min with $0.1 \%$ Triton X-100. After washing twice with PBS $1 \times$ and incubating for 30 min with BSA $2 \% / P B S 1 \times$, the cells were treated with the staining solution containing the AlexaFluor 680 phalloidin dye. Two additional washing steps with PBS $1 \times$ followed before the coverslip was mounted on a microscope coverslip containing a drop of the DAPI nuclear staining dye. The internalization and subcellular localization of the stained pDNA was assessed in a Leica SP8 inverted confocal microscope at ex/em 679/702 nm for the AlexaFluor 680 phalloidin dye, ex/em 488/520nm for the PicoGreen dye, and ex/em 360/460 nm for the DAPI nucleus stain.

\section{Results}

\subsection{Categorization of $\beta$-Sheet Structures and Key $\beta$-Sheet Interactions}

We investigated the self-assembly properties of designed peptides KYRSGAITIGY and KYKGAIIGNIK using independent REMD simulations. Within the simulations, the peptides frequently formed $\beta$-sheet structures comprising two-, three-, four-, five-, and six-stranded $\beta$-sheet structures (Figure 1). Two-stranded $\beta$-sheet structures were observed in both parallel and antiparallel conformations (Figure 1). Three-, four-, five-, and six-stranded $\beta$-sheet structures were observed in parallel, antiparallel, and mixed conformations (Figure 1). As in References [24,26,28,39,45,46], structures comprising mixed conformations, in which the peptides formed at least one pair of parallel and one pair of antiparallel $\beta$-sheet conformations, or complex conformations, in which one peptide formed $\beta$-sheet interactions with more than two separate peptides, were not investigated as they are not expected to be representative of naturally occurring amyloid fibrils. In line with the dominant configuration of the designable scaffolds that were used to produce the designed peptides sequences, 
both peptides showed overall higher tendency to form antiparallel $\beta$-sheet structures over parallel $\beta$-sheet structures (Figure 1C-J). We focused our subsequent investigation on antiparallel $\beta$-sheets which appeared to be predominantly formed. Thus, we extracted the antiparallel four-, five-, and six-stranded $\beta$-sheet structures for further analysis, as they are more likely to represent naturally occurring fibrils than the less complex two- and three-stranded $\beta$-sheet structures.

Using these structures, we calculated the propensities of any two residues belonging to separate adjacent $\beta$-sheet bonded peptides to form intermolecular $\beta$-bridge interactions (Figure 2). In the designed peptide KYRSGAITIGY, the residues involved in $\beta$-bridge interactions were predominantly within the GAITIG motif (Figure 2A,C,E). In the designed peptide KYKGAIIGNIK, the residues involved in $\beta$-bridge interactions were predominantly within the GAIIGN motif (Figure 2B,D,F). Importantly, for both peptides, the designed residues were not involved in $\beta$-bridge interactions, indicating that the designed residues may be exposed and possess functional properties, including cell penetration and DNA binding.

\subsection{Identification of Well-Aligned and Highly Ordered $\beta$-Sheet Conformation Using Polar $\left(P_{1}\right)$ and Nematic $\left(P_{2}\right)$ Order Parameters}

We determined the degree of alignment and order of the peptides within the four-, five-, and six-stranded antiparallel $\beta$-sheet structures based on $P_{1}$ and $P_{2}$ parameters. For both of the designed peptides, KYRSGAITIGY and KYKGAIIGNIK, similarly to our previous studies $[31,34,36]$, highly ordered and well-aligned antiparallel $\beta$-sheet structures predominantly occurred within four-stranded, rather than within five- or six-stranded, antiparallel $\beta$-sheet structures, potentially due to the larger population of four-stranded antiparallel $\beta$-sheet structures. Thus, we constructed free-energy landscapes based on the $P_{1}$ and $P_{2}$ parameters corresponding to the four-stranded antiparallel $\beta$-sheet structures (Figure 3A,B). From the free-energy basin, indicated by black dotted lines in Figure $3 A, B$, we extracted the highly ordered and well-aligned four-stranded antiparallel $\beta$-sheet structures, as these structures can potentially correspond to the elementary $\beta$-sheet structural units of the naturally occurring fibrils. Representative conformations of the four-stranded antiparallel $\beta$-sheet structures are shown in Figure 3C,D. The ensembles of highly ordered and well-aligned four-stranded antiparallel $\beta$-sheet structures for both the designed peptides were collected, and they are analyzed below to determine the functionality of the designed residues.

\subsection{Structural Analysis of the Four-Stranded Highly Ordered and Well-Aligned Structures}

In the four-stranded highly ordered and well-aligned antiparallel $\beta$-sheet structures of the designed peptides, the amyloid steric zipper comprised residues GAITIG for KYRSGAITIGY and residues GAIIGN for KYKGAIIGNIK, in line with our previous analysis (Figure 2). Apart from this, we observed that the designed residues of both peptides rarely formed specific interactions with neighboring residues, but rather formed infrequent interactions with nearby residues; thus, such interactions are not analytically described here.

We determined the degree of solvent accessibility of the designed residues within the highly ordered and well-aligned four-stranded antiparallel $\beta$-sheet structures to assess their exposure and, thus, their potential functionality. The degree of solvent accessibility of the designed residues is presented in Table 1. For both of the designed peptides, KYRSGAITIGY and KYKGAIIGNIK, the degree of solvent accessibility of all four designed residues, with respect to the initial scaffolds, was above 0.40 . According to our previous study on a peptide with sequence $\mathrm{NH}_{3}{ }^{+}-\mathrm{RGDSGAITIGC}-\mathrm{CONH}{ }_{2}$, the solvent accessibility of rationally designed Cys was $0.34 \pm 0.09$, which was experimentally shown to be adequately exposed for potential metal binding properties [36]. Thus, the designed residues of the two peptides of the current study should be considered adequately solvent-exposed for DNA-binding and cell-penetrating functionality.

Combined, the sufficient degree of exposure of the designed residues and the low instances of the designed residues interacting with other residues within the highly ordered and well-aligned 
four-stranded antiparallel $\beta$-sheet structures support that the designed residues could potentially yield cell-penetrating and DNA-binding properties. It is important to note here that that the CPP properties are expected to be an outcome of the exposed residues displayed at the surface of the amyloid fibril, since the peptides self-assemble into fibrils and do not exist as individual molecules.

Table 1. Degree of solvent accessibility of the four designed residues in the two designed peptides KYRSGAITIGY and KYKGAIIGNIK. The four designed residues in each peptide are in bold. The degree of solvent accessibility was calculated for the side chains of the designed residues based on the definitions provided in References [34,36].

\begin{tabular}{|c|c|c|c|c|}
\hline Peptide & $\begin{array}{l}\text { Residue } \\
\text { Position } 1\end{array}$ & $\begin{array}{c}\text { Residue } \\
\text { Position } 2\end{array}$ & $\begin{array}{c}\text { Residue } \\
\text { Position } 3\end{array}$ & $\begin{array}{c}\text { Residue } \\
\text { Position } 11\end{array}$ \\
\hline $\mathrm{NH}_{3}{ }^{+}-\mathrm{KYRSGAITIGY}-\mathrm{CONH}_{2}$ & $0.58 \pm 0.06$ & $0.45 \pm 0.10$ & $0.49 \pm 0.08$ & $0.43 \pm 0.11$ \\
\hline $\mathrm{NH}_{3}{ }^{+}-\mathrm{KYKGAIIGNIK}-\mathrm{CONH}_{2}$ & $0.63 \pm 0.06$ & $0.42 \pm 0.09$ & $0.53 \pm 0.06$ & $0.53 \pm 0.07$ \\
\hline
\end{tabular}

\subsection{Designer Peptides KK and KY Self-Assemble into Positively Charged Amyloid Fibrils}

Both peptides $\mathrm{NH}_{3}{ }^{+}-\mathrm{KYKGAIIGNIK}-\mathrm{CONH}_{2}(\mathrm{KK})$ and $\mathrm{NH}_{3}{ }^{+}-\mathrm{KYRSGAITIGY}-\mathrm{CONH}_{2}(\mathrm{KY})$ were designed to contain a beta-sheet-forming core, GAIIG and GAITIG, respectively, that was reported to self-assemble into amyloid fibrils in vivo and in vitro [31,32]. To assess if our beta-sheet-containing sequences corresponded to amyloid-like morphologies after self-assembly, FE-SEM and TEM observations were performed. We further validated that the peptides can self-assemble into amyloid fibrils with Congo red, one of the most commonly used dyes for amyloid detection. Both peptide powders, after being dissolved in sterile deionized water, acquired a fibrillar morphology of long, straight, randomly oriented fibrils with widths in the range of 10-20 nm as observed under FE-SEM (Figures 4A and 5A) and TEM (Figures 6A and 7A). Moreover, the addition of Congo red stain to the incubated peptides uncovered the amyloid nature of the fibrils due to the yellow-green birefringence of the peptides under a crossed polarizer (Figures $4 \mathrm{~B}$ and 5B). A combination of positively charged residues (Arg and Lys) at the designable positions on both scaffolds resulted in a positive zeta potential, indicating the cationic peptide $\mathrm{KK}$ at $32.3 \pm 0.91 \mathrm{mV}$ and $\mathrm{KY}$ at $31.2 \pm 2.19 \mathrm{mV}$ (Table 2).

Table 2. The average zeta potential of the cationic amyloid peptides. pDNA—plasmid DNA.

\begin{tabular}{|c|c|c|}
\hline pDNA/Peptide Ratio & $\begin{array}{c}\text { Zeta Potential (mV) } \\
\mathrm{NH}_{3}{ }^{+}-\text {KYKGAIIGNIK-CONH }\end{array}$ & $\mathrm{NH}^{+}{ }^{-}-\mathrm{KYRSGAITIGY}-\mathrm{CONH}_{2}$ \\
\hline Peptide only & $32.3 \pm 0.91$ & $31.2 \pm 2.19$ \\
\hline $1: 5000$ & $27.45 \pm 0.9$ & $28.8 \pm 0.21$ \\
\hline $1: 2500$ & $26.9 \pm 0.67$ & $24.1 \pm 1.25$ \\
\hline $1: 1250$ & $24.9 \pm 0.66$ & $14.8 \pm 1.72$ \\
\hline $1: 625$ & $22.1 \pm 2.92$ & $13.7 \pm 2.75$ \\
\hline $1: 312$ & $1.95 \pm 1.02$ & $4.2 \pm 0.74$ \\
\hline
\end{tabular}




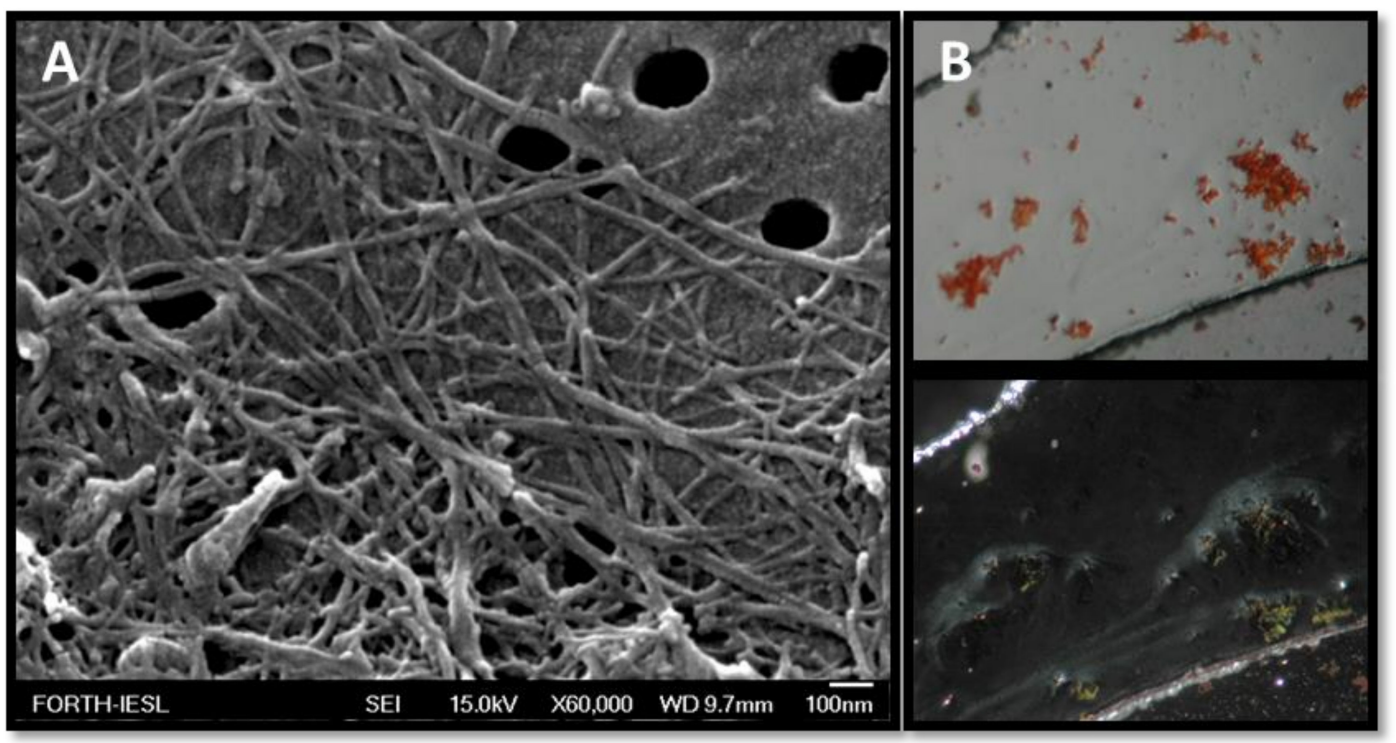

Figure 4. (A) Field-emission SEM (FE-SEM) picture of the self-assembled peptide $\mathrm{NH}_{3}{ }^{+}-\mathrm{KYKGAIIGNIK-}$ $\mathrm{CONH}_{2}(\mathrm{KK})$ after incubation in sterile double-distilled water for three days. Distinct fibrillar morphology is observed. FE-SEM scale bar $=100 \mathrm{~nm}$. (B) Congo red staining confirms the formation of amyloid fibrils due to the yellow-green birefringence under crossed polarizer. Top: without the use of a crossed polarizer; bottom: with the use of a crossed polarizer. Magnification $=30 \times$.
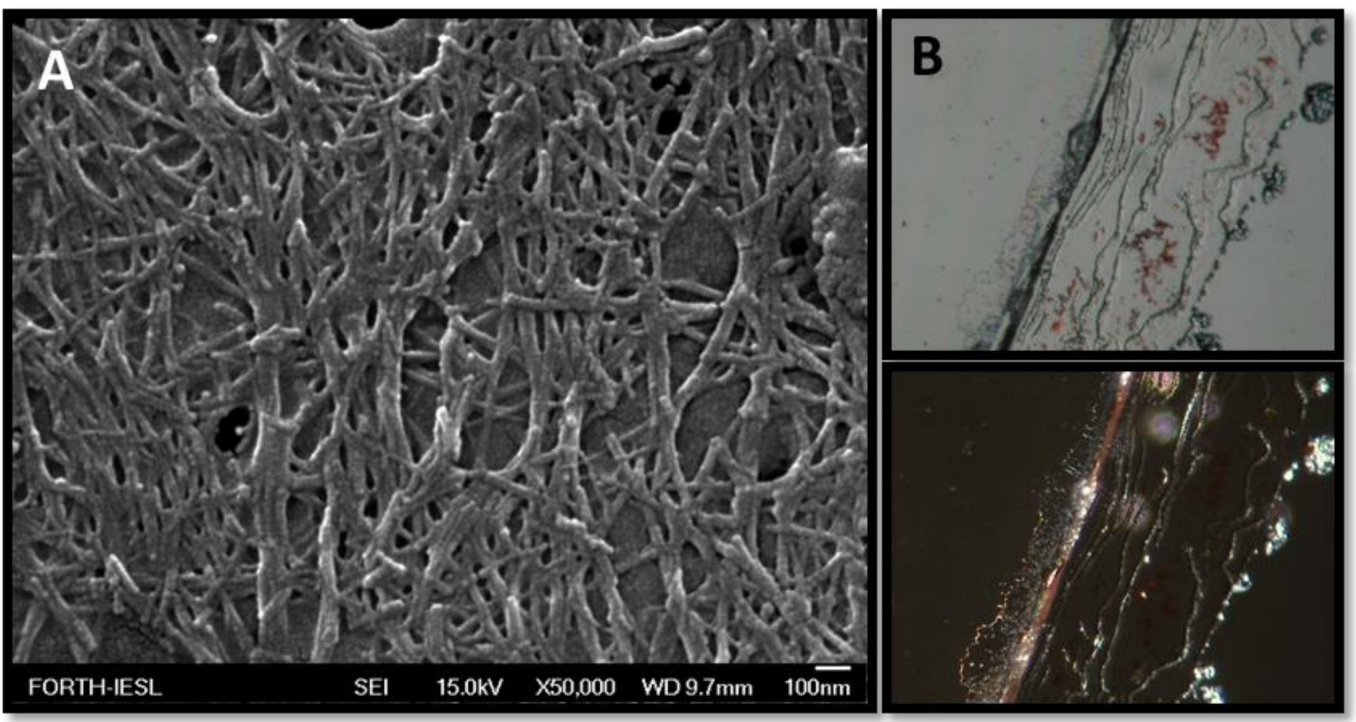

Figure 5. (A) FE-SEM picture of the self-assembled peptide $\mathrm{NH}_{3}{ }^{+}-\mathrm{KYRSGAITIGY}-\mathrm{CONH}_{2}(\mathrm{KY})$ after incubation in sterile double-distilled water for three days. Distinct fibrillar morphology is observed. FE-SEM scale bar $=100 \mathrm{~nm}$. (B) Congo red staining confirms the formation of amyloid fibrils due to the yellow-green birefringence under crossed polarizer. Top: without the use of a crossed polarizer; bottom: with the use of a crossed polarizer. Magnification $=30 \times$. 


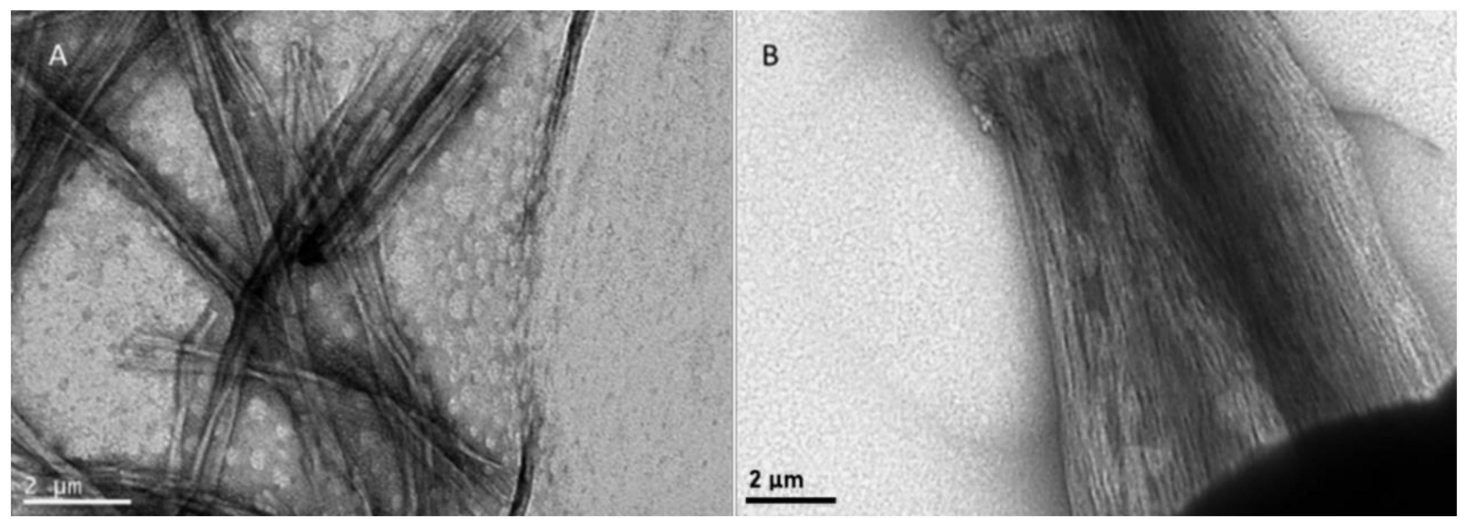

Figure 6. TEM micrographs of the $\mathrm{NH}_{3}{ }^{+}-\mathrm{KYKGAIIGNIK-CONH}{ }_{2}$ peptide fibrils negatively stained with $2 \%$ uranyl acetate (A) before incubation with plasmid DNA (pDNA), and (B) after incubation with pDNA for $1 \mathrm{~h}$ in a 1:1000 DNA/peptide ratio. Change in the conformation of the fibrils after binding with pDNA, from a random orientation to a more aligned configuration with adherent fibrils, suggests DNA binding. Scale bar $=2 \mu \mathrm{m}$.
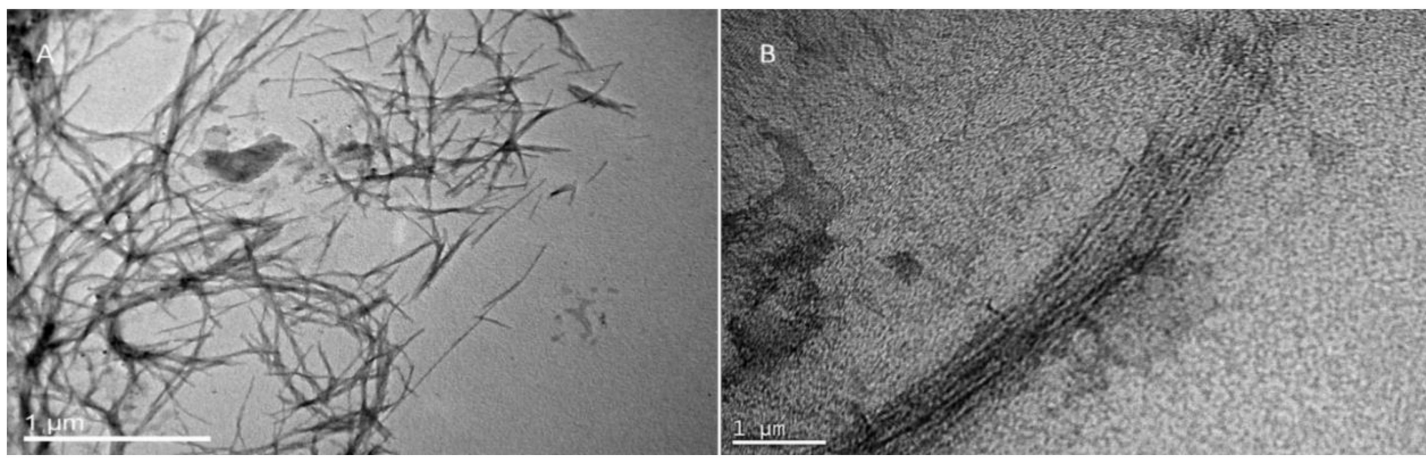

Figure 7. TEM micrographs of the $\mathrm{NH}_{3}{ }^{+}-\mathrm{KYRSGAITIGY-CONH} 2$ peptide fibrils negatively stained with $2 \%$ uranyl acetate (A) before incubation with pDNA, and (B) after incubation with pDNA for $1 \mathrm{~h}$ in a 1:1000 DNA/peptide ratio. Change in the conformation of the fibrils after binding with pDNA, from a random orientation to a more aligned configuration with adherent fibrils, suggests DNA binding. Scale bar $=1 \mu \mathrm{m}$.

\subsection{Amyloid Cationic Peptides Package pDNA by Forming Stable Fibrillar Complexes}

To examine the binding and condensation ability of our amyloidal peptides with pDNA, gel retardation, a PicoGreen fluorescence assay, and TEM observations were performed.

The pDNA complexes were prepared with the two cationic peptides at DNA/peptide ratios ranging from 1:20 to 1:400. After a 1-h incubation period, they were analyzed for changes in their mobility by a $0.5 \%$ agarose gel electrophoresis. Both peptides bound and completely retarded pDNA in the wells (Figure 8). It should also be noted a slight decrease in the intensity of the Gel-Red stain fluorescence at the highest concentrations of the KK peptide complexes, suggesting further fluorescence quenching due to the additional pDNA association. The aim of this experiment was to identify the DNA condensation capacity of the peptides, since plasmid DNA has a highly negative charge and each of the peptide monomers can contribute positive charges attributed to the arginine and lysine residues and also to the unprotected amino group at the $\mathrm{N}$-terminal end. Concluding the above results, we verified that our peptides can fully package pDNA. 

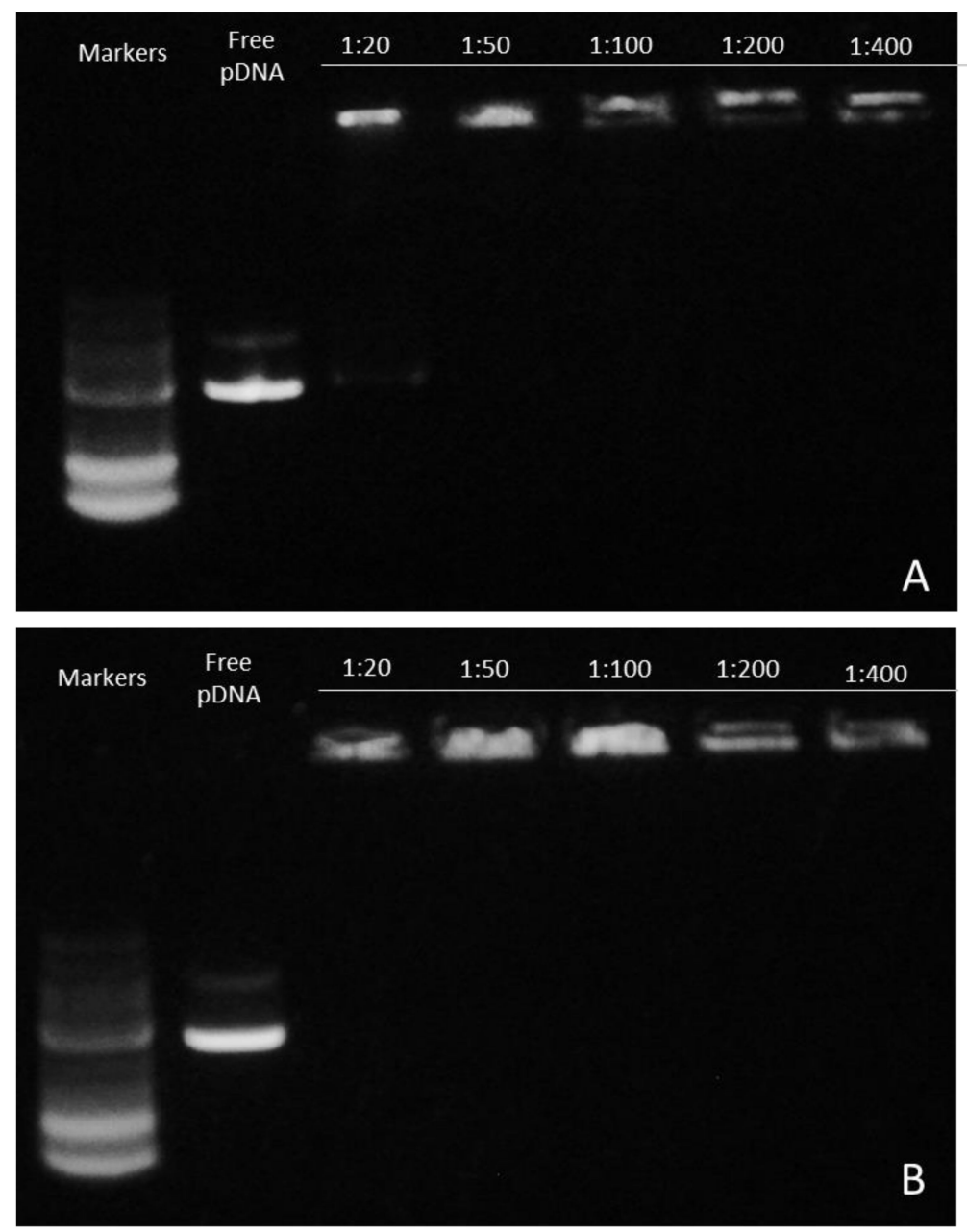

Figure 8. Gel retardation assay for the binding efficiency of the amyloidal peptides with pDNA. Peptides (A) KK and (B) KY were complexed with 500 ng of pGL3-SV40 in pDNA/peptide ratios varying from 1:20 to 1:400 for $30 \mathrm{~min}$. Formed complexes were run on a $0.5 \%$ agarose gel. Free pDNA was used as control.

As an additional confirmation for the binding of the peptides to pDNA, a PicoGreen fluorescence quenching assay was conducted. In the assay, pDNA was mixed with the PicoGreen dye that emits a strong fluorescent signal when excited at $488 \mathrm{~nm}$. Quenching of this signal indicates packaging of the DNA and subsequent binding. Comparing the remaining fluorescence after the complex formation with the fluorescence of the naked pDNA, the percentage of the fluorescence loss corresponds to the level of DNA packaging by the peptides. Complexes of pDNA with the peptides achieved maximal quenching of the PicoGreen signal in all of the DNA-peptide ratios tested (Figure 9), which confirms that, even at low concentrations, our amyloid cationic peptides possess a high binding capacity, a result that is in agreement with the gel retardation assay experiment. 


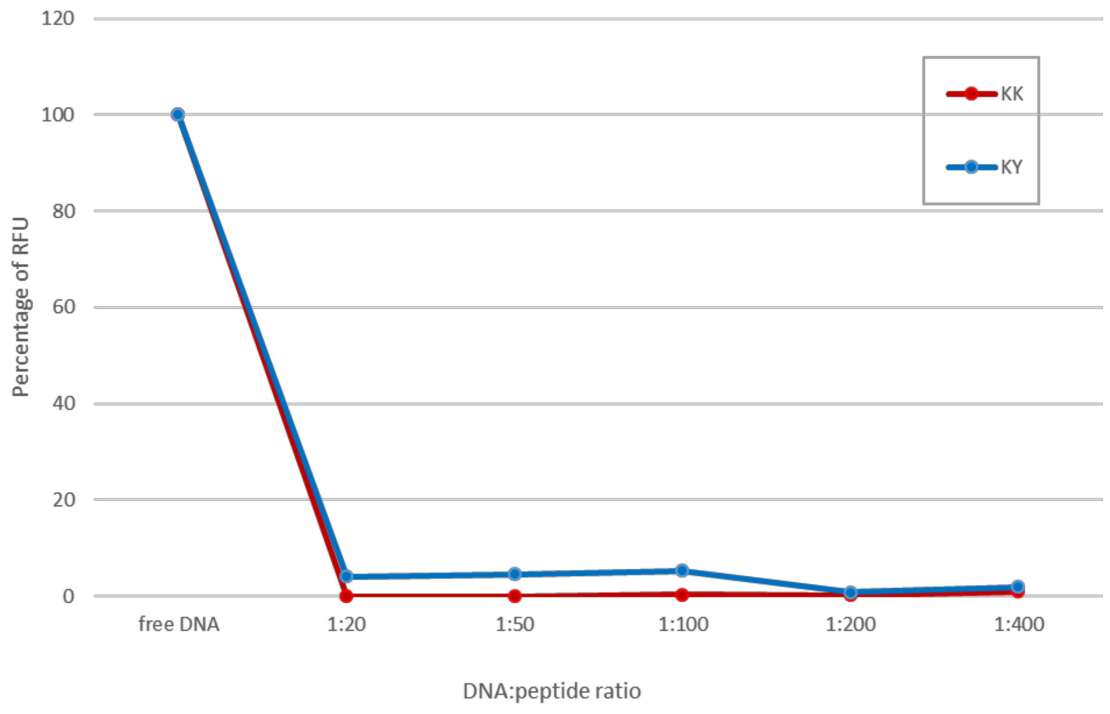

Figure 9. Percentage of pDNA binding to the amyloidal peptides according to PicoGreen fluorescence quenching assay. $\mathrm{NH}_{3}{ }^{+}-\mathrm{K} Y K G A I I G N I K-\mathrm{CONH}_{2}$ (red) and $\mathrm{NH}_{3}{ }^{+}-\mathrm{KYRSGAITIGY}-\mathrm{CONH}_{2}$ (blue) were mixed with a constant concentration of pDNA $(500 \mathrm{ng})$ in various ratios for $30 \mathrm{~min}$. Complexes were further stained with the PicoGreen dsDNA dye. The fluorescence intensity of the complexes was then measured and normalized compared to the fluorescence intensity of the PicoGreen bound to free pDNA. The percentage of free and unbound pDNA was measured according to the fluorescence quenching level. Low fluorescence percentages indicate DNA binding to the peptides and subsequent quenching of the fluorescence signal.

\subsection{DNA Binding Alters the Morphology of the Fibrils}

We next investigated the effect of DNA binding on the morphology of the fibrils after incubation. Interestingly, while amyloid peptides KK and KY exhibited a randomly oriented architecture (Figures 6A and 7A), when these peptides were incubated with the pDNA molecules, they seemed to adhere to each other, affording a more aligned assembly (Figures 6B and 7B). This bundling of the fibrils could be mediated by the electrostatic attraction between negatively charged pDNA molecules and cationic residues belonging to adjacent fibrils/beta sheets.

\subsection{Long-Term Stability of the pDNA/Peptide Complexes}

Moreover, KK-DNA and KY-DNA complexes displayed excellent stability in long-term storage (over four months) at room temperature or in refrigerated conditions without the use of any additives. Furthermore, after lyophilization of the peptide-DNA complex solutions and subsequent resuspension in water, no apparent loss of their binding capability and stability was observed, after testing with the aforementioned methods (results not shown).

\subsection{Internalization of the Cationic Peptides and pDNA-Peptide Complexes and Their Subcellular Localization}

As concluded in the computational analysis of the two peptides, the designed cationic residues have a high probability of being exposed and accessible for cell penetration and DNA binding. We examined the cell internalization propensity of the two peptides by employing the Proteostat ${ }^{\circledR}$ staining assay. The PROTEOSTAT ${ }^{\circledR}$ dye is a red fluorescent molecular rotor dye, which specifically intercalates into the cross-beta spine of protein and peptide structures. This binding inhibits the dye rotation and leads to a strong fluorescence emission [64]. Peptides KK and KY were incubated with HEK293T cells and were subsequently stained with the Proteostat ${ }^{\circledR}$ dye. Cell were also stained with the nuclear Hoechst dye to better distinguish the cell nucleus location. Both peptides seemed to internalize in the cell and to localize in the cytoplasm (Figure 10). For additional internalization detection studies concerning the pDNA-peptide complexes, kidney embryonic cells HEK293T were 
incubated with the pre-stained peptide-pGL3 DNA complexes for $4 \mathrm{~h}$ and subsequently imaged in a confocal fluorescent microscope. We detected the pre-stained plasmid with Picogreen mainly in the nuclear area (Figure 11), indicating successful transfection and transition of pDNA in the nucleus within $4 \mathrm{~h}$ with the use of the peptide carriers. Figure 11A shows only the PicoGreen stain control. PicoGreen, despite being able to stain free dsDNA, is not considered a cell-permeable dye. To confirm that the green fluorescence was attributed predominantly to the pre-stained pDNA inserted in the nucleus, and not PicoGreen interference, cells were incubated for $4 \mathrm{~h}$ only with the PicoGreen stain in the same concentrations used for staining of the pDNA. Only a dim green fluorescence was observed in the cell nucleus, indicating that PicoGreen unspecific staining did not interfere with our observations. Cells incubated with the pre-stained pDNA/peptide complex are shown in Figure 11B, where only the cell nucleus (blue) and actin (red) were visualized, whereas, in Figure 11C, the PicoGreen (green) and actin (red) filters were applied. An intense green fluorescence signal in the nucleus was detected in Figure 11C, indicative of the effective internalization and transfer of the pre-stained SV40-pDNA into the nuclear area. Eventually, when all the filters were applied, the cell nucleus acquired a blue/green color attributed to the mixed color of the DAPI and PicoGreen fluorescence signals (Figure 11D).
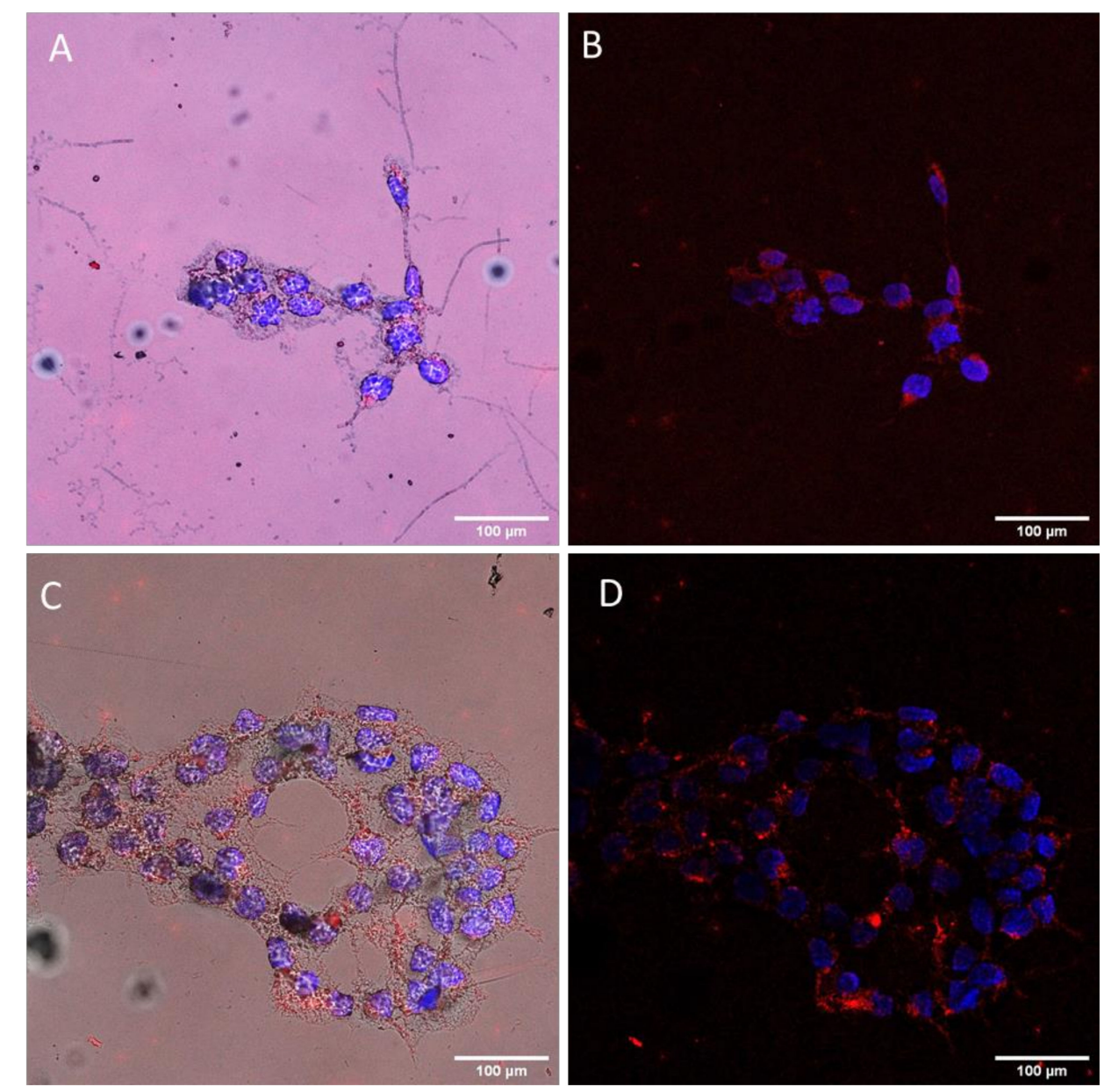

Figure 10. Cellular uptake of the cationic amyloidal peptides. HEK293T cells were exposed to $25 \mu \mathrm{g}$ of KK and KY peptide, followed by a $24-\mathrm{h}$ incubation. For confocal microscopy observations, cells were washed and stained with a mixture of the Proteostat ${ }^{\circledR}$ dye that binds to the amyloid fibrils and Hoechst 33,342 for nuclear stain. Pictures (A,B) correspond to the KK peptide, and pictures (C,D) correspond to the KY peptide. For pictures $(\mathbf{A}, \mathbf{C})$, the bright-field illumination form was applied additionally, to circumscribe the limits of the cell membranes. Moreover, z-stacks for each peptide were obtained to ensure the internalization and not the external cell adhesion of the peptides (results not shown). Scale bar $=100 \mu \mathrm{m}$. 

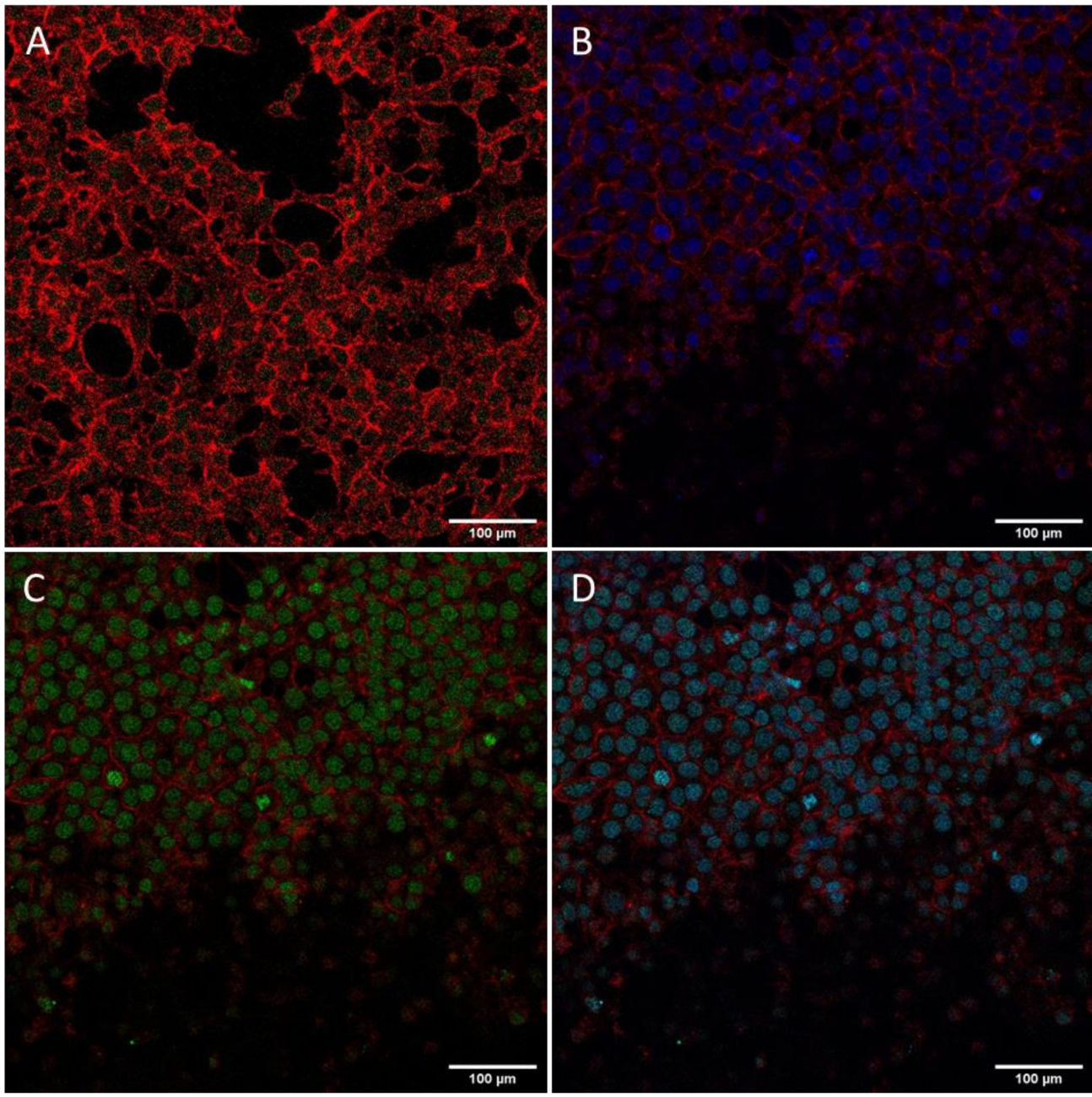

Figure 11. pGL3-SV40 delivery into the nucleus with the aid of the KK peptide. HEK293T cells were treated for $4 \mathrm{~h}$ with a pre-stained PicoGreen pDNA/KK complex at a 1:5000 ratio. PicoGreen dye without adding the DNA/peptide complex was used as a control. Cells were washed and stained with AlexaFluor680 phalloidin for visualizing cell membranes (red) and DAPI for visualizing the nucleus (blue). Confocal image of the cells (A) incubated only with the PicoGreen stain control, (B) after incubation for $4 \mathrm{~h}$ with the complex applying only the DAPI (blue) and phalloidin (red) filter, and (C) with the PicoGreen filter for pDNA visualization (green) and phalloidin (red). (D) A merged picture with the three stains (all filters applied) confirms the successful transportation of the pGL3-SV40 into the nucleus. KY rendered similar results. Scale bar $=100 \mu \mathrm{m}$.

\subsection{Transfection Studies of the Cell-Penetrating Amyloid Peptide-pDNA Complexes}

We investigated the ability of our amyloid peptides to deliver the luciferase-expressing plasmid pGL3-SV40 into the cells and trigger effective gene expression. For gene expression studies, kidney embryonic cells HEK293T were incubated with the peptide/DNA complexes (Table 3) for $48 \mathrm{~h}$, followed by a luciferase activity detection assay. The KK-pDNA and KY-pDNA complexes mediated detectable and satisfactory transfection levels of the pGL3-SV40 plasmid as detected by the luciferase expression levels (Figure 12). KK-DNA and KY-DNA complexes had their highest transfection efficacy at a DNA/peptide ratio of 1:5000, while decreasing the peptide concentration to a 1:312 ratio led to decreased transfection efficacy for both peptides. This can be attributed to the higher overall positive charge of the complexes in ratios where the peptide concentration was increased. As depicted in Table 2, KK and KY complexes started from a 1:5000 DNA/peptide ratio with a positive zeta potential of $27.45 \pm 0.9 \mathrm{mV}$ and $28.8 \pm 0.21 \mathrm{mV}$, respectively. Keeping a constant DNA concentration of $50 \mathrm{ng}$ and gradually 
decreasing the peptide concentration from $250 \mu \mathrm{g}$ to $15.6 \mu \mathrm{g}$, the DNA/peptide ratio decreased to 1:312 and resulted in a decreased zeta potential of $1.95 \pm 1.02 \mathrm{mV}$ and $4.2 \pm 0.74 \mathrm{mV}$ for the KK-pDNA and KY-pDNA complexes, respectively. The results indicate that there is a direct correlation between the amount of higher positively charged peptide complexes and the transfection levels. Moreover, it should be noted that KY-DNA complexes achieved higher luciferase gene expression level compared to KK-DNA complexes.

Table 3. Summary of the peptide and pDNA concentrations used for the formation of the complexes.

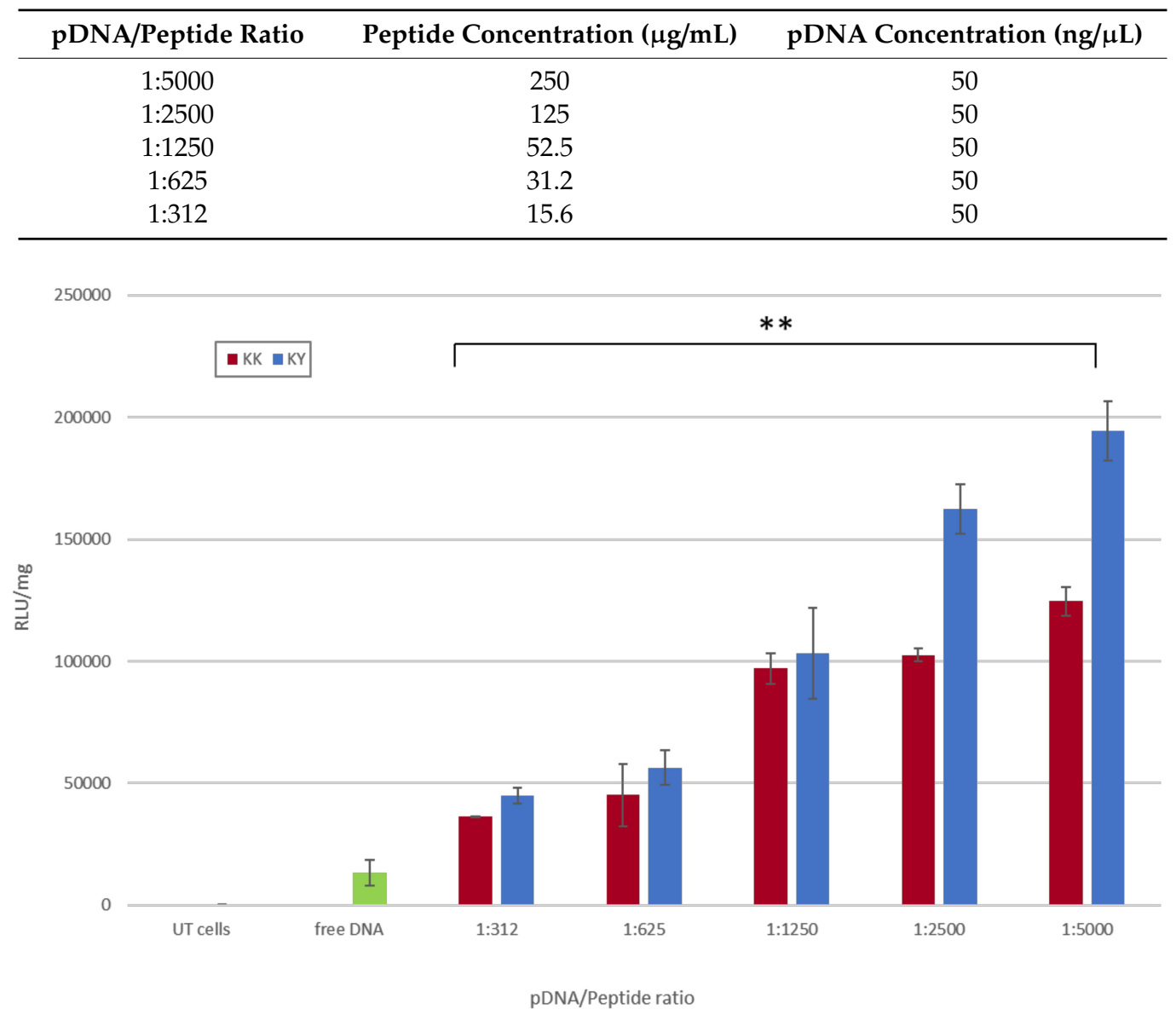

Figure 12. Levels of expression of the luciferase protein in the HEK293T cells after transfection with the pGL3-SV40/KK and pGL3-SV40/KY complexes at different ratios for $4 \mathrm{~h}$ and a subsequent incubation period of $48 \mathrm{~h}$. Untreated cells and free pDNA were used as controls. ** denotes the significant difference in the RLU (Relative Light Units)/mg between the untreated cells and the transfected cells $(p<0.01)$.

\subsection{Designed Peptides Are Toxic to Bacteria But Not to Mammalian Cells}

An ideal gene delivery vehicle exhibits very limited or no cytotoxicity to the cells being transfected. Indications of a toxic carrier are initially assessed by cell viability assays such as the MTT test. To confirm that the designed peptides have limited or no cytotoxicity, we carried out transfections with the KK and KY peptides at increasing concentrations and measured the impact on the cell line using the MTT assay. No significant cytotoxicity related to KK and KY peptides was observed; therefore, the peptides can be considered non-toxic to the cell line in the conditions tested (Figure 13). We further examined the antimicrobial potency of our cationic amyloid peptides against a common Gram-negative bacterial species, E. coli BL21 DE3. It should be noted that both cationic peptides KK and KY inhibited bacterial population growth. However, KY had better antimicrobial activity by reducing the bacterial 
population to $50 \%$ at concentrations around $0.375 \mathrm{mg} / \mathrm{mL}$ compared to $\mathrm{KK}$, which required higher concentrations for the same result (Figure 14).

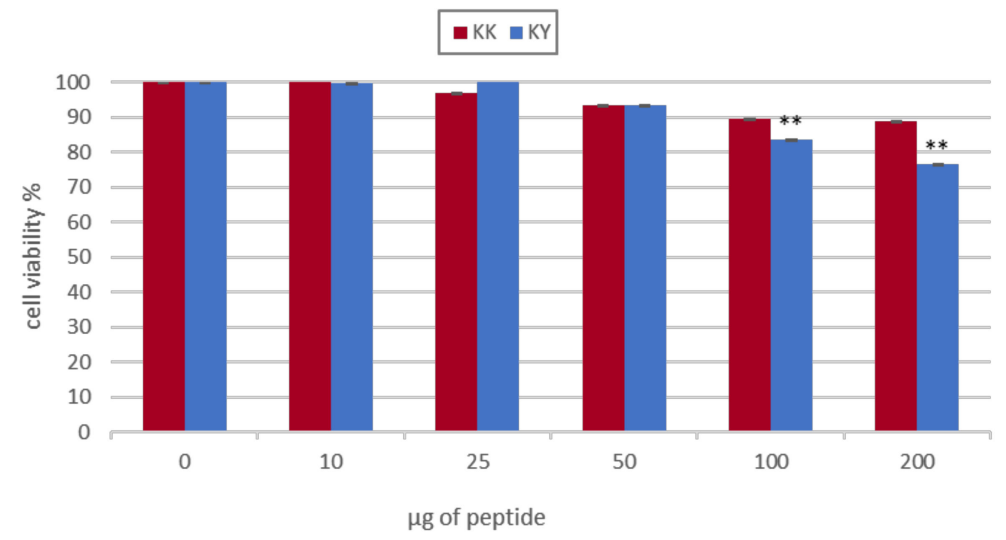

Figure 13. Thiazolyl blue tetrazolium bromide (MTT) cell viability assay results of the amyloid peptides incubated for $48 \mathrm{~h}$ in HEK293T cells. KK peptide is represented with red, and KY peptide is represented with blue. Various concentrations of the peptides were used varying from 10 to $200 \mu \mathrm{g}$. Results are expressed as a percentage value of control cells cultured without the addition of peptides (control $=100 \%)$. ${ }^{* *}$ denotes the significant difference in cell viability between the untreated cells and the transfected cells with the peptides $(p<0.01)$.

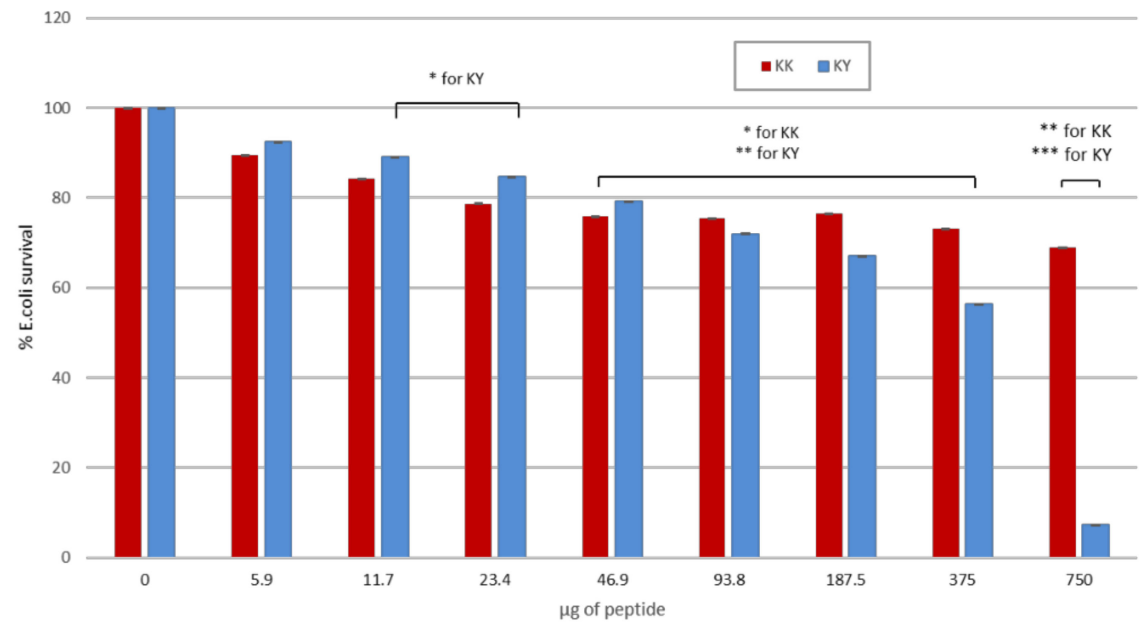

Figure 14. Antimicrobial activity of peptides KK (red) and KY (blue) against Escherichia coli bacteria after treatment with increasing concentrations of the peptides. The cultures of bacteria were treated for $24 \mathrm{~h}$ in $37^{\circ} \mathrm{C}$, followed by absorbance measurements at $600 \mathrm{~nm}$. Untreated cultures $(0 \mu \mathrm{g}$ of peptide) were used as control, and the measurements were performed in triplicate. ${ }^{*} p<0.05,{ }^{* *} p<0.01$, $* * * p<0.0001$.

\section{Discussion}

In the present study, we employed computational methods toward the design of amyloid cell-penetrating biomaterials with DNA-binding functionalities. The computational design was based on the amyloid scaffolds YATGAIIGNII [31] and RGDSGAITIGC [36], which contain the $\beta$-sheet cores GAIIG and GAITIG, and which were mutated at key non- $\beta$-sheet positions at their termini, namely, at residue positions one, two, three, and eleven. We hypothesized that inserting positively charged residues (Arg and Lys) at these specific positions would favor cell penetration and DNA binding, as recorded in similar studies $[65,66]$. We purposely left the N-terminal end unprotected for potential involvement of the positively charged amino group in the electrostatic interactions of the peptide. Moreover, aromatic residues in the order $\mathrm{Y}>\mathrm{W}>\mathrm{F}$ are abundant in proteins interacting with 
DNA [37]. Thus, we hypothesized that tyrosine residues at key positions would additionally favor DNA interaction with our scaffolds.

To elucidate if the novel peptide sequences $\mathrm{NH}_{3}{ }^{+}-\mathrm{KYKGAIIGNIK-CONH}{ }_{2}$ and $\mathrm{NH}_{3}{ }^{+}-$ KYRSGAITIGY-CONH${ }_{2}$ (KK and KY, respectively) had the desired self-assembly properties, we independently investigated the designed peptides using REMD simulations, which revealed that they can spontaneously self-assemble, predominantly in antiparallel $\beta$-sheets. Importantly, the designed residues in both scaffolds were not involved in $\beta$-bridge interactions, suggesting that these residues are exposed and could possess cell-penetrating and DNA-binding properties. The amyloid nature of KK and KY was further experimentally verified when the peptides, dissolved in sterile filtered double-distilled water, formed the characteristic amyloid fibrils as assessed by TEM, FE-SEM, and Congo red staining.

Important characteristics should be taken into consideration when utilizing positively charged peptides for transferring cargo into cells, especially for gene therapy purposes: (1) effective binding of the oligonucleotide of interest, (2) efficient cellular membrane translocation of the peptide, (3) transfer of the CPP conjugate into the cell and subsequent release of the oligonucleotide, and (4) very limited or no cytotoxicity at all.

The common characteristic of cationic CPPs is their positive net charge, which originates from their basic residues, arginine and lysine. The positive net charge plays a pivotal role in mediating the internalization of the naked peptide and a variety of therapeutic cargoes into mammalian cells. TAT-derived peptides [67], synthetic polyarginines [68], and penetratin [69] are among the most effective representatives of the cationic class of cell-penetrating peptides. Both designer peptides exhibited a positive zeta potential, with $32.3 \pm 0.91 \mathrm{mV}$ for the KK peptide and $31.2 \pm 2.19 \mathrm{mV}$ for the KY peptide, confirming the exposure of the arginine and lysine residues and also classifying the peptide assemblies as positively charged.

CPP internalization can be attributed to various mechanisms. Routes can be divided into two broad categories: direct penetration of the plasma membrane through interaction of the positively charged peptides with the negatively charged membrane components and phospholipid bilayer [6] or through energy-dependent endocytic pathways, especially when peptides are associated with cargo molecules. Moreover, the internalization process can be dependent on various factors, for example, concentration of the peptide, and properties of the cargo molecules or the cell line [4]. Amyloid fibrils possess cell adhesive properties and can mimic the fibrillar morphology of the extracellular matrix through functionalization with cell-adhesive ligands [70,71]. Moreover, positively charged amyloid nanosheets can also be used as a "docking station" for DNA condensation and retroviral transduction enhancement $[16,17,20]$. However, due to their extended fibrillar morphology, they were not considered until now as possible candidates for cell internalization and gene carriers. In the present study, the designed peptides successfully achieved non-cytotoxic internalization into the HEK293T cells after an incubation period of $24 \mathrm{~h}$, as revealed by MTT and Proteostat aggresome staining. However, the exact cell uptake mechanisms remain to be elucidated.

For a facile gene transfer application, the peptide carrier should be able to bind and protect the genetic material effectively. Positively charged peptides can interact with the negatively charged phosphate backbone of DNA through electrostatic interactions, leading to condensation of the nucleic-acid biomolecules [72]. DNA-condensing, cell-penetrating peptides must retain their condensation abilities following cell internalization in order to prolong the life of the carried nucleic acid [73] and prevent DNA degradation by cytosolic nucleases [74]. Generally, following endocytosis, a significant amount of internalized DNA is targeted to the lysosomes where it is degraded [75]. Even the remaining "free" DNA has a life expectancy of 50-90 $\mathrm{min}$ in the cytoplasm since it is subject to degradation by nucleases [73]. The presence of a carrier that can protect the DNA integrity is essential for safe pDNA transition into the nucleus. Cationic peptides KK and KY were incubated with the luciferase-carrying plasmid, and their DNA-binding abilities were assessed by gel retardation, a PicoGreen assay, and TEM. Since amyloid fibrils cannot diffuse through the agarose pores during 
electrophoresis due to their morphology, any observed delay in the pDNA migration reflects the extent of the peptide DNA-binding ability. In order to test the DNA-binding capacity of the peptides, we used a high pDNA concentration relative to the peptide concentration. Full retardation of the plasmid band was observed in all of the DNA/peptide ratios tested. Furthermore, the PicoGreen quenching assay showed that, when peptides were mixed with the pre-stained pDNA in the same complex ratios, full quenching of the fluorescent signal was observed. Thus, the gel retardation and fluorescence quenching results point to the DNA condensation ability of the peptides. Interestingly, TEM observation of the peptide-pDNA revealed a change in the arrangement of the fibrils from a randomly oriented fibrillary morphology to bundled assemblies that seem to be connected to each other. We speculate that this alteration is a result of electrostatic interactions between the negatively charged DNA and the positively charged residues emanating from different fibrillar moieties.

Peptide transfection studies showed efficient gene delivery results by the $\mathrm{pDNA} / \mathrm{KK}$ and $\mathrm{pDNA} / \mathrm{KY}$ complexes in HEK293T cells after a minimal incubation period of $4 \mathrm{~h}$. The delivery efficiency was significantly increased with the increase in peptide concentration. For both peptides, the zeta potential of the complexes increased, from $1.95 \pm 1.02$ to $27.45 \pm 0.9$ for $\mathrm{pDNA} / \mathrm{KK}$ and from $4.2 \pm 0.74$ to $28.8 \pm 0.21$ for $\mathrm{pDNA} / \mathrm{KY}$ (corresponding to DNA/peptide ratios from 1:312 to 1:5000). Therefore, as the added peptide in the complex increased, the DNA negative charge was completely neutralized, and positive charges were in excess. Concurrently, the transfection efficiency increased along with the increase in the overall charge complex from 1:312 to 1:5000. It was reported that the excess of positive charge in the transfecting DNA/peptide complex leads to a more efficient gene transfer. The positive charges may serve in part as a means for electrostatic binding and condensation of DNA [76], and in part for the translocation through the negatively charged anionic phospholipids and/or for the neutralization of various charge factors on the cell surface. It is plausible to conclude that, as the negative charge of the complexes was reduced, the transduction efficiency increased, resulting in a direct correlation of the pDNA/peptide complex charge and the gene delivery efficacy. Furthermore, KY-DNA complexes achieved higher luciferase gene expression levels compared to KK-DNA complexes. This cannot be attributed solely to the difference in overall charge, since the zeta potential measurements fluctuated in the same levels. Arginine-containing sequences may have an advantage in rapid cell penetration due to the ability of the guanidine head to form bidentate hydrogen bonds with the negatively charged membrane constituents [77]. Recent theoretical and experimental studies also point to an important role of arginines in CPP peptides, allowing the peptides to self-associate, thereby enhancing their transduction and potentially their bioavailability [78]. The confocal observations of cells treated with the pre-stained SV40-pGL3 plasmid show that it entered the nucleus in a period of $4 \mathrm{~h}$, as observed from the blue/green overlay on the nuclear area. Figure 15 summarizes the steps leading to the delivery and expression of pDNA by the peptides studied in this work.

Generally, CPPs are designed for noninvasive cargo transport, but they can also possess specific antibacterial activity. Such examples of antimicrobial CPPs are [65] TP-10 [79], MAP [80], TAT [81], penetratin [80,82], pVEC [80], and $\varepsilon$-poly-L-lysines [83], all of which can act as antibacterial agents depending on the peptide concentration and the composition of the bacterial membrane. A proposed mechanism of the cell-penetrating peptides' antimicrobial activity is the carpet-like model, according to which the positively charged domain of the peptides interacts with and binds to the negatively charged phospholipids on the bacterial membrane, covering the cell surface in a carpet like manner. When a certain concentration of the peptide is reached, the membrane is locally destabilized, allowing the passage of the peptides through different perturbation mechanisms [7]. Peptides $\mathrm{NH}_{3}{ }^{+}-\mathrm{KYKGAIIGNIK-CONH}{ }_{2}$ and $\mathrm{NH}_{3}{ }^{+}-\mathrm{KYRSGAITIGY-CONH}{ }_{2}$ are both cationic, cell-penetrating peptides which can self-aggregate into amyloid fibrils. They also exhibited bactericidal activity against the $E$. coli strain tested. The peptide $\mathrm{NH}_{3}{ }^{+}-\mathrm{KYRSGAITIGY-CONH}{ }_{2}$ required a concentration of $0.375 \mathrm{mg} / \mathrm{mL}$ to reduce the bacterial population to $50 \%$, compared to $\mathrm{NH}_{3}{ }^{+}-\mathrm{KYKGAIIGNIK-CONH}{ }_{2}$, which required a higher peptide concentration. Cationic aggregating peptides comprising arginine residues, as well as short aggregation-prone residue stretches, were recently identified via bioinformatics 
approaches in the bacterial proteome and were reported to internalize in mammalian cells. They were also found to be lethal to bacterial cells [14,15]. Their specific toxicity toward bacterial and not mammalian cells involves uptake mechanisms and specific cross-aggregation with bacterial homologous sequences; this cross-aggregation subsequently leads to disruption of bacterial protein homeostasis as a result of the accumulation of protein aggregates [14,15]. Elucidating the mechanism of antimicrobial action of the two peptides reported here will be the subject of future studies. It did not escape our attention that the quasi-homologous sequence SAIIGI was identified with a high cross-aggregation score with E. coli proteins in Reference [14], and the designed RSAIIGIIRRPRSAIIGIIRR sequence was predicted to have antibacterial action [14]. It is plausible to hypothesize that the antibacterial activity of the two peptides reported here could follow the same mechanism as that reported in Reference [14], i.e., a cell-penetrating activity mediated by positively charged residues and cross-interaction of the amyloid cores with bacterial sequences, leading to aggregates that disrupt bacterial proteostasis. However, the exact mechanism remains to be elucidated in future studies.

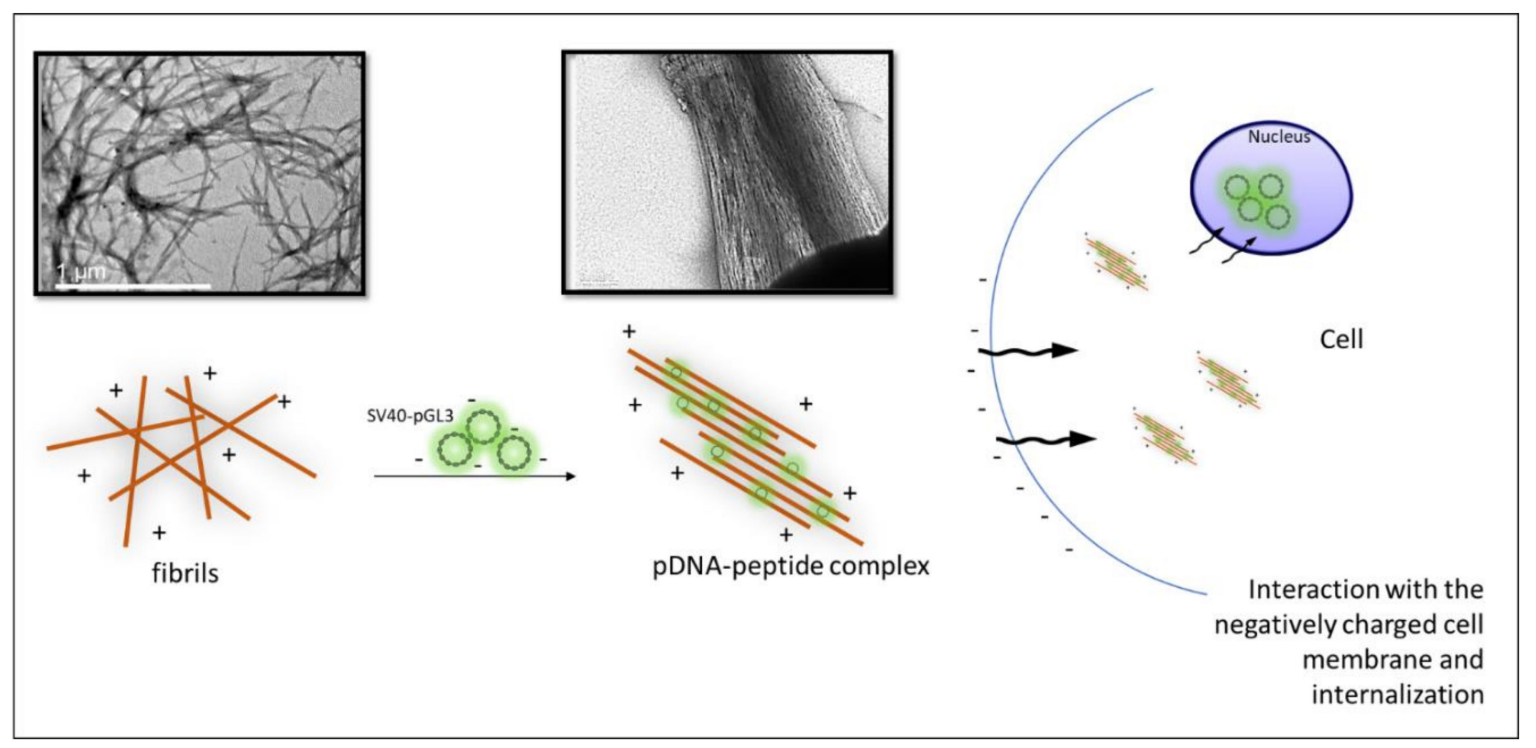

Figure 15. Schematic representation of the pDNA/peptide complex formation and cell uptake through electrostatic interactions. Objects are not drawn to scale.

\section{Conclusions}

In this study, we rationally designed two functional peptides that combine amyloid fibril characteristics and beneficial cell penetrating properties. The novel peptide sequences comprised the fibrillar $\beta$-sheet core of peptides GAIIG and GAITIG and self-assembled spontaneously into amyloid fibrils when dissolved in water. Through incorporation of the positively charged amino acids arginine and lysine and the aromatic residue tyrosine at carefully selected residue positions, we succeeded in mimicking the cell internalization, as well as DNA-binding and -condensing abilities, of previously in-depth tested cell-penetrating peptides. More importantly, the DNA/peptide fibrillar assemblies were able to transfect and enhance the luciferase protein expression in a charge- and peptide concentration-dependent manner. Moreover, these peptides were able to effectively and drastically decrease E. coli's culture population under the conditions tested.

Amyloid-forming peptides are gaining increasing importance in biomedical applications, including tissue engineering, nanovaccine engineering, and biosensing [70,84]. We anticipate that our designer amyloid materials could constitute a stepping stone for utilizing amyloids as novel biomaterial scaffolds that combine cell penetration and gene transfer with antibacterial properties. Future studies could focus on combining additional properties to the currently designed materials, such as the transfer of siRNAs and protein therapeutic cargos, as well as examining and improving their antimicrobial activity for different bacteria and microbes. Amyloid-forming CPPs present advantages compared to 
traditional CPPs, such as the possibility to engineer different delivery functionalities onto the same self-assembling scaffold. Moreover, the cross-seeding between the amyloid-forming CPPs and other amyloid peptides, a well-known property of amyloidogenic proteins and peptides [85-87], could potentially be exploited toward multifunctional biomaterial design.

Author Contributions: Conceptualization, A.M. and P.T.; methodology, S.V.R.J., A.A.O., C.K., A.M., and P.T.; software, S.V.R.J., A.A.O., and P.T.; validation, C.K., A.K., S.V.R.J., A.A.O., G.V., P.T., and A.M.; formal analysis, C.K., S.V.R.J., and A.A.O.; investigation, C.K., S.V.R.J., and A.A.O; resources, G.V., A.K., P.T., and A.M.; data curation, A.K., S.V.R.J., A.A.O., P.T., and A.M.; writing-original draft preparation, C.K., S.V.R.J., A.A.O., P.T., and A.M.; writing-review and editing, C.K., S.V.R.J., A.A.O., A.K., P.T., and A.M.; visualization, C.K., S.V.R.J., and A.A.O.; supervision, A.K., P.T., and A.M.; project administration, A.M. and P.T.; funding acquisition, A.M. and P.T. All authors have read and agreed to the published version of the manuscript.

Funding: This study was supported by start-up funding from the Artie McFerrin Department of Chemical Engineering of Texas A\&M awarded to P.T. C.K. and A.M. acknowledge support of this work by the project "Advanced Research Activities in Biomedical and Agro alimentary Technologies" (MIS 5002469), which is implemented under the "Action for the Strategic Development on the Research and Technological Sector", funded by the Operational Program "Competitiveness, Entrepreneurship, and Innovation" (NSRF 2014-2020) and co-financed by Greece and the European Union (European Regional Development Fund).

Acknowledgments: We are grateful to Georgios Halepakis, Aleka Manoussaki, and Sevasti Papadogiorgaki for technical assistance with TEM and FE-SEM experiments. Also, we wish to thank Takis Makatounakis for his help with the mammalian cell cultures, and Mohandas from the Polymer and Science group for his help with the zeta potential measurements. All MD simulations and free-energy calculations were performed on the Ada supercomputing cluster at the Texas A\&M High-Performance Research Computing Facility.

Conflicts of Interest: The authors declare no conflicts of interest. The funders had no role in the design of the study; in the collection, analyses, or interpretation of data; in the writing of the manuscript, or in the decision to publish the results.

\section{References}

1. Kwok, A.; Hart, S.L. Comparative structural and functional studies of nanoparticle formulations for DNA and siRNA delivery. Nanomedicine 2011, 7, 210-219. [CrossRef]

2. Kwok, A.; McCarthy, D.; Hart, S.L.; Tagalakis, A.D. Systematic Comparisons of Formulations of Linear Oligolysine Peptides with siRNA and Plasmid DNA. Chem. Biol. Drug Des. 2016, 87, 747-763. [CrossRef] [PubMed]

3. Vaughan, E.E.; Dean, D.A. Intracellular trafficking of plasmids during transfection is mediated by microtubules. Mol. Ther. J. Am. Soc. Gene Ther. 2006, 13, 422-428. [CrossRef] [PubMed]

4. Lehto, T.; Ezzat, K.; Wood, M.J.A.; El Andaloussi, S. Peptides for nucleic acid delivery. Adv. Drug Deliv Rev. 2016, 106, 172-182. [CrossRef] [PubMed]

5. Suhorutsenko, J.; Oskolkov, N.; Arukuusk, P.; Kurrikoff, K.; Eriste, E.; Copolovici, D.M.; Langel, U. Cell-penetrating peptides, PepFects, show no evidence of toxicity and immunogenicity in vitro and in vivo. Bioconjugate Chem. 2011, 22, 2255-2262. [CrossRef]

6. Guidotti, G.; Brambilla, L.; Rossi, D. Cell-Penetrating Peptides: From Basic Research to Clinics. Trends Pharmacol. Sci. 2017, 38, 406-424. [CrossRef]

7. Raucher, D.; Ryu, J.S. Cell-penetrating peptides: Strategies for anticancer treatment. Trends Mol. Med. 2015, 21, 560-570. [CrossRef]

8. Bechara, C.; Sagan, S. Cell-penetrating peptides: 20 years later, where do we stand? FEBS Lett. 2013, 587, 1693-1702. [CrossRef]

9. Wang, F.; Wang, Y.; Zhang, X.; Zhang, W.; Guo, S.; Jin, F. Recent progress of cell-penetrating peptides as new carriers for intracellular cargo delivery. J. Control. Release Off. J. Control. Release Soc. 2014, 174, 126-136. [CrossRef]

10. Ignatovich, I.A.; Dizhe, E.B.; Pavlotskaya, A.V.; Akifiev, B.N.; Burov, S.V.; Orlov, S.V.; Perevozchikov, A.P. Complexes of plasmid DNA with basic domain 47-57 of the HIV-1 Tat protein are transferred to mammalian cells by endocytosis-mediated pathways. J. Biol. Chem. 2003, 278, 42625-42636. [CrossRef]

11. Freimann, K.; Arukuusk, P.; Kurrikoff, K.; Vasconcelos, L.D.F.; Veiman, K.L.; Uusna, J.; Margus, H.; Garcia-Sosa, A.T.; Pooga, M.; Langel, U. Optimization of in vivo DNA delivery with NickFect peptide vectors. J. Control. Release Off. J. Control. Release Soc. 2016, 241, 135-143. [CrossRef] [PubMed] 
12. Freimann, K.; Arukuusk, P.; Kurrikoff, K.; Parnaste, L.; Raid, R.; Piirsoo, A.; Pooga, M.; Langel, U. Formulation of Stable and Homogeneous Cell-Penetrating Peptide NF55 Nanoparticles for Efficient Gene Delivery In Vivo. Mol. Ther. Nucleic Acids 2018, 10, 28-35. [CrossRef] [PubMed]

13. Veiman, K.L.; Mager, I.; Ezzat, K.; Margus, H.; Lehto, T.; Langel, K.; Kurrikoff, K.; Arukuusk, P.; Suhorutsenko, J.; Padari, K.; et al. PepFect14 peptide vector for efficient gene delivery in cell cultures. Mol. Pharm. 2013, 10, 199-210. [CrossRef] [PubMed]

14. Khodaparast, L.; Gallardo, R.; Louros, N.N.; Michiels, E.; Ramakrishnan, R.; Ramakers, M.; Claes, F.; Young, L.; Shahrooei, M.; Wilkinson, H.; et al. Aggregating sequences that occur in many proteins constitute weak spots of bacterial proteostasis. Nat. Commun. 2018, 9, 866. [CrossRef]

15. Bednarska, N.G.; van Eldere, J.; Gallardo, R.; Ganesan, A.; Ramakers, M.; Vogel, I.; Baatsen, P.; Staes, A.; Goethals, M.; Hammarstrom, P.; et al. Protein aggregation as an antibiotic design strategy. Mol. Microbiol. 2016, 99, 849-865. [CrossRef]

16. Dai, B.; Li, D.; Xi, W.; Luo, F.; Zhang, X.; Zou, M.; Cao, M.; Hu, J.; Wang, W.; Wei, G.; et al. Tunable assembly of amyloid-forming peptides into nanosheets as a retrovirus carrier. Proc. Natl. Acad. Sci. USA 2015, 112, 2996-3001. [CrossRef]

17. Yolamanova, M.; Meier, C.; Shaytan, A.K.; Vas, V.; Bertoncini, C.W.; Arnold, F.; Zirafi, O.; Usmani, S.M.; Muller, J.A.; Sauter, D.; et al. Peptide nanofibrils boost retroviral gene transfer and provide a rapid means for concentrating viruses. Nat. Nanotechnol. 2013, 8, 130-136. [CrossRef]

18. Li, D.; Jones, E.M.; Sawaya, M.R.; Furukawa, H.; Luo, F.; Ivanova, M.; Sievers, S.A.; Wang, W.; Yaghi, O.M.; Liu, C.; et al. Structure-based design of functional amyloid materials. J. Am. Chem. Soc. 2014, 136, 18044-18051. [CrossRef]

19. Munch, J.; Rucker, E.; Standker, L.; Adermann, K.; Goffinet, C.; Schindler, M.; Wildum, S.; Chinnadurai, R.; Rajan, D.; Specht, A.; et al. Semen-derived amyloid fibrils drastically enhance HIV infection. Cell 2007, 131, 1059-1071. [CrossRef]

20. Kirti, S.; Patel, K.; Das, S.; Shrimali, P.; Samanta, S.; Kumar, R.; Chatterjee, D.; Ghosh, D.; Kumar, A.; Tayalia, P.; et al. Amyloid Fibrils with Positive Charge Enhance Retroviral Transduction in Mammalian Cells. Acs Biomater. Sci. Eng. 2019, 5, 126-138. [CrossRef]

21. Cherny, I.; Gazit, E. Amyloids: Not only pathological agents but also ordered nanomaterials. Angezw. Chem. Int. Ed. 2008, 47, 4062-4069. [CrossRef] [PubMed]

22. Chiti, F.; Dobson, C.M. Protein misfolding, functional amyloid, and human disease. Annu. Rev. Biochem. 2006, 75, 333-366. [CrossRef] [PubMed]

23. Orr, A.A.; Wordehoff, M.M.; Hoyer, W.; Tamamis, P. Uncovering the Binding and Specificity of beta-Wrapins for Amyloid-beta and alpha-Synuclein. J. Phys. Chem. B 2016, 120, 12781-12794. [CrossRef] [PubMed]

24. Huang, Y.; Mucke, L. Alzheimer mechanisms and therapeutic strategies. Cell 2012, 148, 1204-1222. [CrossRef]

25. Lashuel, H.A.; Overk, C.R.; Oueslati, A.; Masliah, E. The many faces of alpha-synuclein: From structure and toxicity to therapeutic target. Nat. Rev. Neurosci. 2013, 14, 38-48. [CrossRef]

26. Villar-Pique, A.; Lopes da Fonseca, T.; Outeiro, T.F. Structure, function and toxicity of alpha-synuclein: The Bermuda triangle in synucleinopathies. J. Neurochem. 2016, 139 (Suppl. 1), 240-255. [CrossRef]

27. Adler-Abramovich, L.; Gazit, E. The physical properties of supramolecular peptide assemblies: From building block association to technological applications. Chem. Soc. Rev. 2014, 43, 6881-6893. [CrossRef]

28. Wei, G.; Su, Z.Q.; Reynolds, N.P.; Arosio, P.; Hamley, I.W.; Gazit, E.; Mezzenga, R. Self-assembling peptide and protein amyloids: From structure to tailored function in nanotechnology. Chem. Soc. Rev. 2017, 46, 4661-4708. [CrossRef]

29. Hafner-Bratkovic, I. Prions, prionoid complexes and amyloids: The bad, the good and something in between. Swiss Med. Wkly. 2017, 147. [CrossRef]

30. Jackson, M.P.; Hewitt, E.W. Why Are Functional Amyloids Non-Toxic in Humans? Biomolecules 2017, 7, 71. [CrossRef]

31. Kokotidou, C.; Jonnalagadda, S.V.R.; Orr, A.A.; Seoane-Blanco, M.; Apostolidou, C.P.; van Raaij, M.J.; Kotzabasaki, M.; Chatzoudis, A.; Jakubowski, J.M.; Mossou, E.; et al. A novel amyloid designable scaffold and potential inhibitor inspired by GAIIG of amyloid beta and the HIV-1 V3 loop. Febs Lett. 2018, 592, 1777-1788. [CrossRef] [PubMed] 
32. Papanikolopoulou, K.; Schoehn, G.; Forge, V.; Forsyth, V.T.; Riekel, C.; Hernandez, J.F.; Ruigrok, R.W.H.; Mitraki, A. Amyloid fibril formation from sequences of a natural beta-structured fibrous protein, the adenovirus fiber. J. Biol. Chem. 2005, 280, 2481-2490. [CrossRef] [PubMed]

33. Tamamis, P.; Kasotakis, E.; Mitraki, A.; Archontis, G. Amyloid-Like Self-Assembly of Peptide Sequences from the Adenovirus Fiber Shaft: Insights from Molecular Dynamics Simulations. J. Phys. Chem. B 2009, 113, 15639-15647. [CrossRef] [PubMed]

34. Jonnalagadda, S.V.R.; Kokotidou, C.; Orr, A.A.; Fotopoulou, E.; Henderson, K.J.; Choi, C.H.; Lim, W.T.; Choi, S.J.; Jeong, H.K.; Mitraki, A.; et al. Computational Design of Functional Amyloid Materials with Cesium Binding, Deposition, and Capture Properties. J. Phys. Chem. B 2018, 122, 7555-7568. [CrossRef] [PubMed]

35. Kasotakis, E.; Mossou, E.; Adler-Abramovich, L.; Mitchell, E.P.; Forsyth, V.T.; Gazit, E.; Mitraki, A. Design of Metal-Binding Sites onto Self-Assembled Peptide Fibrils. Biopolymers 2009, 92, 164-172. [CrossRef] [PubMed]

36. Deidda, G.; Jonnalagadda, S.V.R.; Spies, J.W.; Ranella, A.; Mossou, E.; Forsyth, V.T.; Mitchell, E.P.; Bowler, M.W.; Tamamis, P.; Mitraki, A. Self-Assembled Amyloid Peptides with Arg-Gly-Asp (RGD) Motifs as Scaffolds for Tissue Engineering. Acs Biomater. Sci. Eng. 2017, 3, 1404-1416. [CrossRef]

37. Wu, J.; Yan, S.; Tang, L.; Hu, D. Computational analysis of propensities of amino acids and nucleotides usage at protein-nucleic acid interfaces. In Proceedings of the International Conference on Information Science and Technology, Nanjing, Jiangsu, China, 26-28 March 2011; pp. 1342-1349.

38. Jonnalagadda, S.V.R.; Ornithopoulou, E.; Orr, A.A.; Mossou, E.; Forsyth, V.T.; Mitchell, E.P.; Bowler, M.W.; Mitraki, A.; Tamamis, P. Computational design of amyloid self-assembling peptides bearing aromatic residues and the cell adhesive motif Arg-Gly-Asp. Mol. Syst. Des. Eng. 2017, 2, 321-335. [CrossRef]

39. Madani, F.; Lindberg, S.; Langel, U.; Futaki, S.; Gräslund, A. Mechanisms of cellular uptake of cell-penetrating peptides. J. Biophys. 2011, 2011, 414729. [CrossRef]

40. Agrawal, P.; Bhalla, S.; Usmani, S.S.; Singh, S.; Chaudhary, K.; Raghava, G.P.; Gautam, A. CPPsite 2.0: A repository of experimentally validated cell-penetrating peptides. Nucleic Acids Res. 2016, 44, D1098-D1103. [CrossRef]

41. Tamamis, P.; Kasotakis, E.; Archontis, G.; Mitraki, A. Combination of Theoretical and Experimental Approaches for the Design and Study of Fibril-Forming Peptides. In Protein Design: Methods and Applications; Köhler, V., Ed.; Springer: New York, NY, USA, 2014; pp. 53-70.

42. Tamamis, P.; Archontis, G. Amyloid-like self-assembly of a dodecapeptide sequence from the adenovirus fiber shaft: Perspectives from molecular dynamics simulations. J. Non-Cryst. Solids 2011, 357, 717-722. [CrossRef]

43. Tamamis, P.; Terzaki, K.; Kassinopoulos, M.; Mastrogiannis, L.; Mossou, E.; Forsyth, V.T.; Mitchell, E.P.; Mitraki, A.; Archontis, G. Self-Assembly of an Aspartate-Rich Sequence from the Adenovirus Fiber Shaft: Insights from Molecular Dynamics Simulations and Experiments. J. Phys. Chem. B 2014, 118, 1765-1774. [CrossRef] [PubMed]

44. Swendsen, R.H.; Wang, J.-S. Replica Monte Carlo Simulation of Spin-Glasses. Phys. Rev. Lett. 1986, 57, $2607-2609$. [CrossRef] [PubMed]

45. Hukushima, K.; Nemoto, K. Exchange Monte Carlo Method and Application to Spin Glass Simulations. J. Phys. Soc. Jpn. 1995, 65, 1604-1608. [CrossRef]

46. Hansmann, U.H.E. Parallel tempering algorithm for conformational studies of biological molecules. Chem. Phys. Lett. 1997, 281, 140-150. [CrossRef]

47. Sugita, Y.; Okamoto, Y. Replica-exchange molecular dynamics method for protein folding. Chem. Phys. Lett. 1999, 314, 141-151. [CrossRef]

48. Sanbonmatsu, K.Y.; García, A.E. Structure of Met-enkephalin in explicit aqueous solution using replica exchange molecular dynamics. Proteins Struct. Funct. Bioinform. 2002, 46, 225-234. [CrossRef]

49. Nymeyer, H.; Gnanakaran, S.; García, A.E. Atomic Simulations of Protein Folding, Using the Replica Exchange Algorithm. In Methods in Enzymology; Academic Press: Cambridge, MA, USA, 2004; Volume 383, pp. 119-149.

50. Brooks, B.R.; Brooks, C.L., 3rd; Mackerell, A.D., Jr.; Nilsson, L.; Petrella, R.J.; Roux, B.; Won, Y.; Archontis, G.; Bartels, C.; Boresch, S.; et al. CHARMM: The biomolecular simulation program. J. Comput. Chem. 2009, 30, 1545-1614. [CrossRef] 
51. Brooks, B.R.; Bruccoleri, R.E.; Olafson, B.D.; States, D.J.; Swaminathan, S.; Karplus, M. CHARMM: A program for macromolecular energy, minimization, and dynamics calculations. J. Comput. Chem. 1983, 4, 187-217. [CrossRef]

52. Haberthür, U.; Caflisch, A. FACTS: Fast analytical continuum treatment of solvation. J. Comput. Chem. 2008, 29, 701-715. [CrossRef]

53. Seeber, M.; Felline, A.; Raimondi, F.; Muff, S.; Friedman, R.; Rao, F.; Caflisch, A.; Fanelli, F. Wordom: A user-friendly program for the analysis of molecular structures, trajectories, and free energy surfaces. J. Comput. Chem. 2011, 32, 1183-1194. [CrossRef]

54. Seeber, M.; Cecchini, M.; Rao, F.; Settanni, G.; Caflisch, A. Wordom: A program for efficient analysis of molecular dynamics simulations. Bioinformatics 2007, 23, 2625-2627. [CrossRef] [PubMed]

55. Kabsch, W.; Sander, C. Dictionary of protein secondary structure: Pattern recognition of hydrogen-bonded and geometrical features. Biopolymers 1983, 22, 2577-2637. [CrossRef] [PubMed]

56. Cecchini, M.; Rao, F.; Seeber, M.; Caflisch, A. Replica exchange molecular dynamics simulations of amyloid peptide aggregation. J. Chem. Phys. 2004, 121, 10748-10756. [CrossRef] [PubMed]

57. Allen, M.P.; Tildesley, D.J. Computer Simulation of Liquids; Oxford Science: Oxford, UK, 1987.

58. Krivov, S.V. The Free Energy Landscape Analysis of Protein (FIP35) Folding Dynamics. J. Phys. Chem. B 2011, 115, 12315-12324. [CrossRef] [PubMed]

59. Tamamis, P.; Floudas, C.A. Molecular recognition of CXCR4 by a dual tropic HIV-1 gp120 V3 loop. Biophys. J. 2013, 105, 1502-1514. [CrossRef] [PubMed]

60. Tamamis, P.; Floudas, C.A. Molecular recognition of CCR5 by an HIV-1 gp120 V3 loop. PLoS ONE 2014, 9, e95767. [CrossRef] [PubMed]

61. Tamamis, P.; Floudas, C.A. Elucidating a Key Anti-HIV-1 and Cancer-Associated Axis: The Structure of CCL5 (Rantes) in Complex with CCR5. Sci. Rep. 2014, 4, 5447. [CrossRef]

62. Tamamis, P.; Floudas, C.A. Elucidating a Key Component of Cancer Metastasis: CXCL12 (SDF-1 $\alpha$ ) Binding to CXCR4. J. Chem. Inf. Model. 2014, 54, 1174-1188. [CrossRef]

63. Wiegand, I.; Hilpert, K.; Hancock, R.E. Agar and broth dilution methods to determine the minimal inhibitory concentration (MIC) of antimicrobial substances. Nat. Protoc. 2008, 3, 163-175. [CrossRef]

64. Shen, D.; Coleman, J.; Chan, E.; Nicholson, T.P.; Dai, L.; Sheppard, P.W.; Patton, W.F. Novel cell- and tissue-based assays for detecting misfolded and aggregated protein accumulation within aggresomes and inclusion bodies. Cell Biochem. Biophys. 2011, 60, 173-185. [CrossRef]

65. Copolovici, D.M.; Langel, K.; Eriste, E.; Langel, U. Cell-penetrating peptides: Design, synthesis, and applications. ACS Nano 2014, 8, 1972-1994. [CrossRef] [PubMed]

66. Farkhani, S.M.; Valizadeh, A.; Karami, H.; Mohammadi, S.; Sohrabi, N.; Badrzadeh, F. Cell penetrating peptides: Efficient vectors for delivery of nanoparticles, nanocarriers, therapeutic and diagnostic molecules. Peptides 2014, 57, 78-94. [CrossRef] [PubMed]

67. Vives, E.; Brodin, P.; Lebleu, B. A truncated HIV-1 Tat protein basic domain rapidly translocates through the plasma membrane and accumulates in the cell nucleus. J. Biol. Chem. 1997, 272, 16010-16017. [CrossRef] [PubMed]

68. Futaki, S.; Suzuki, T.; Ohashi, W.; Yagami, T.; Tanaka, S.; Ueda, K.; Sugiura, Y. Arginine-rich peptides. An abundant source of membrane-permeable peptides having potential as carriers for intracellular protein delivery. J. Biol. Chem. 2001, 276, 5836-5840. [CrossRef]

69. Derossi, D.; Joliot, A.H.; Chassaing, G.; Prochiantz, A. The third helix of the Antennapedia homeodomain translocates through biological membranes. J. Biol. Chem. 1994, 269, 10444-10450.

70. Das, S.; Jacob, R.S.; Patel, K.; Singh, N.; Maji, S.K. Amyloid Fibrils: Versatile Biomaterials for Cell Adhesion and Tissue Engineering Applications. Biomacromolecules 2018, 19, 1826-1839. [CrossRef]

71. Gras, S.L.; Tickler, A.K.; Squires, A.M.; Devlin, G.L.; Horton, M.A.; Dobson, C.M.; MacPhee, C.E. Functionalised amyloid fibrils for roles in cell adhesion. Biomaterials 2008, 29, 1553-1562. [CrossRef]

72. Bloomfield, V.A. DNA condensation. Curr. Opin. Struct. Biol. 1996, 6, 334-341. [CrossRef]

73. Lechardeur, D.; Sohn, K.J.; Haardt, M.; Joshi, P.B.; Monck, M.; Graham, R.W.; Beatty, B.; Squire, J.; O'Brodovich, H.; Lukacs, G.L. Metabolic instability of plasmid DNA in the cytosol: A potential barrier to gene transfer. Gene Ther. 1999, 6, 482-497. [CrossRef]

74. Wolfert, M.A.; Seymour, L.W. Chloroquine and amphipathic peptide helices show synergistic transfection in vitro. Gene Ther. 1998, 5, 409-414. [CrossRef] 
75. Dean, D.A.; Strong, D.D.; Zimmer, W.E. Nuclear entry of nonviral vectors. Gene Ther. 2005, 12, 881-890. [CrossRef] [PubMed]

76. Zhang, F.; Andreassen, P.; Fender, P.; Geissler, E.; Hernandez, J.F.; Chroboczek, J. A transfecting peptide derived from adenovirus fiber protein. Gene Ther. 1999, 6, 171-181. [CrossRef] [PubMed]

77. Rothbard, J.B.; Jessop, T.C.; Wender, P.A. Adaptive translocation: The role of hydrogen bonding and membrane potential in the uptake of guanidinium-rich transporters into cells. Adv. Drug Deliv. Rev. 2005, 57, 495-504. [CrossRef] [PubMed]

78. Tesei, G.; Vazdar, M.; Jensen, M.R.; Cragnell, C.; Mason, P.E.; Heyda, J.; Skepo, M.; Jungwirth, P.; Lund, M. Self-association of a highly charged arginine-rich cell-penetrating peptide. Proc. Natl. Acad. Sci. USA 2017, 114, 11428-11433. [CrossRef]

79. Arrighi, R.B.; Ebikeme, C.; Jiang, Y.; Ranford-Cartwright, L.; Barrett, M.P.; Langel, U.; Faye, I. Cell-penetrating peptide TP10 shows broad-spectrum activity against both Plasmodium falciparum and Trypanosoma brucei brucei. Antimicrob. Agents Chemother. 2008, 52, 3414-3417. [CrossRef]

80. Palm, C.; Netzerea, S.; Hallbrink, M. Quantitatively determined uptake of cell-penetrating peptides in non-mammalian cells with an evaluation of degradation and antimicrobial effects. Peptides 2006, 27, 1710-1716. [CrossRef]

81. Zhu, W.L.; Shin, S.Y. Effects of dimerization of the cell-penetrating peptide Tat analog on antimicrobial activity and mechanism of bactericidal action. J. Pept. Sci. Off. Publ. Eur. Pept. Soc. 2009, 15, 345-352. [CrossRef]

82. Zhu, W.L.; Shin, S.Y. Antimicrobial and cytolytic activities and plausible mode of bactericidal action of the cell penetrating peptide penetratin and its lys-linked two-stranded peptide. Chem. Biol. Drug Des. 2009, 73, 209-215. [CrossRef]

83. Yoshida, T.; Nagasawa, T. Epsilon-Poly-L-lysine: Microbial production, biodegradation and application potential. Appl. Microbiol. Biotechnol. 2003, 62, 21-26. [CrossRef]

84. Al-Halifa, S.; Babych, M.; Zottig, X.; Archambault, D.; Bourgault, S. Amyloid self-assembling peptides: Potential applications in nanovaccine engineering and biosensing. Pept. Sci. 2019, 111. [CrossRef]

85. Atsmon-Raz, Y.; Miller, Y. Molecular Mechanisms of the Bindings between Non-Amyloid beta Component Oligomers and Amylin Oligomers. J. Phys. Chem. B 2016, 120, 10649-10659. [CrossRef] [PubMed]

86. Atsmon-Raz, Y.; Miller, Y. Non-Amyloid-beta Component of Human alpha-Synuclein Oligomers Induces Formation of New A beta Oligomers: Insight into the Mechanisms That Link Parkinson's and Alzheimer's Diseases. Acs Chem. Neurosci. 2016, 7, 46-55. [CrossRef] [PubMed]

87. Baram, M.; Atsmon-Raz, Y.; Ma, B.Y.; Nussinov, R.; Miller, Y. Amylin-A beta oligomers at atomic resolution using molecular dynamics simulations: A link between Type 2 diabetes and Alzheimer's disease. Phys. Chem. Chem. Phys. 2016, 18, 2330-2338. [CrossRef] [PubMed] 